\title{
BPMG - Um Modelo Conceitual para Governança em BPM - Aplicação numa Organização Pública
}

\author{
André Felipe L. Santana, Carina Frota Alves ${ }^{1}$ \\ ${ }^{1}$ Centro de Informática - Universidade Federal de Pernambuco (CIn/UFPE) \\ Av. Jornalista Aníbal Fernandes, s/n - Cidade Universitária 50.740-560 - Recife - PE - \\ Brazil \\ afelipe.santana@gmail.com, cfa@cin.ufpe.br
}

\begin{abstract}
BPM (Business Process Management) Governance is an aspect often seen as critical to the success of BPM in organizations. This seems to be especially true for the public sector, where effectivity, accountability and transparency (three basic governance principles) must be coordinated. However, BPM governance approaches have been characterized as complex and imprecise, with quite different views on the subject, in addition to macro level models that provide little help on how to implement it. In addition, there are a few reports with practical empirical studies on this theme. This paper describes the construction of a conceptual model for governance in BPM (in form of a conceptual data model) and its application in a Brazilian public organization using a design-science approach. The assessment of the model application pointed that it was perceived as being significantly useful to create a common understanding and to support BPM governance in the researched organization.
\end{abstract}

Resumo. Governança em BPM é um aspecto apontado como fundamental para o sucesso efetivo do gerenciamento de processos de negócio. Isso parece ser especialmente verdade no contexto do setor público, onde a efetividade, prestação de contas e transparência (três princípios básicos da governança) precisam ser coordenadas. No entanto, as abordagens dessa governança têm se caracterizado por conceitos complexos e pouco precisos, e modelos em alto nível que oferecem pouca ajuda sobre como implementá-la. Além disso, há um número reduzido de trabalhos empíricos com relatos práticos neste tema. Este trabalho relata a construção de um Modelo Conceitual para Governança em BPM (na forma de um modelo conceitual de dados) e sua aplicação numa organização pública brasileira, utilizando uma abordagem de design-science. A avaliação sobre a aplicação do modelo apontou que ele foi percebido como significativamente útil para criar um entendimento comum bem como para apoiar a estruturação da governança em BPM na organização pesquisada.

\section{Introdução}

Governança é um conceito associado à necessidade de proteção dos investimentos e à sustentabilidade das organizações (Hoogervorst, 2009). Embora o conceito geral não seja novo, o interesse no tema ressurgiu com grande intensidade desde o início dos anos 2000. Isso aconteceu, por um lado, devido a eventos marcantes de fraudes em grandes corporações em nível mundial. Por outro lado, a globalização da economia e uso cada vez mais intenso da tecnologia da informação, que trouxeram inegáveis benefícios e

SANTANA, A. F. L.; ALVES, C. F.

BPMG - Um Modelo Conceitual para Governança em BPM - Aplicação numa Organização Pública

iSys - Revista Brasileira de Sistemas de Informação, Rio de Janeiro, vol. 9, No. 1, pp. 139-167, 2016 
oportunidades às empresas, trouxeram também novos riscos à sua sobrevivência (Hoogervorst, 2009). Por esse motivo, novas formas específicas de governança passaram a ser necessárias em vários aspectos da gestão organizacional como um desdobramento necessário da Governança Corporativa. Dentre essas formas específicas, surge a ideia da governança aplicada ao gerenciamento dos processos de negócio.

Conforme Jeston e Nelis (2008) os requisitos da noção geral de governança são impactantes em BPM em dois aspectos: (i) diretamente nos processos (exigindo requisitos como: transparência das atividades, possibilidade de responsabilização individual dos executores), e (ii) na gestão dos processos (exigindo requisitos como: registros de auditoria, tratamento de exceções, registro de riscos e não-conformidades). Kirchmer (2010) argumenta que a Governança de Processos de Negócio é a fundação necessária para garantir a sustentabilidade e o foco contínuo na inovação e melhorias de processos, e na criação de valor para todas as partes interessadas, tais como clientes, parceiros de negócios, funcionários e acionistas.

Todavia, as abordagens de governança em BPM têm se caracterizado por: apresentarem conceitos complexos e pouco precisos, com visões bastante variadas sobre o tema; modelos em nível muito macro, que oferecem pouca ajuda ou guia sobre como implementar essa forma de governança nas organizações; poucos relatos empíricos sobre o tema descrevendo a implementação dessa forma de governança nas organizações. Considerando esse contexto, este trabalho busca tratar os seguintes problemas de pesquisa expresso nas questões:

- (QP1) Quais são os elementos que devem constituir um modelo conceitual de Governança em BPM e como eles se relacionam?

- (QP2) Como os elementos conceituais de governança em BPM identificados têm sido aplicados na prática?

- (QP3) Quais são as principais barreiras e facilitadores para implantação de um modelo de governança em BPM numa organização?

O restante deste artigo está assim organizado: a Seção 2 traz as bases teóricas que fundamentam os problemas de pesquisa. A Seção 3 apresenta a abordagem metodológica usada na condução do trabalho que teve como eixo a pesquisa-design (design-science research). A Seção 4 apresenta o Modelo BPMG construído em resposta à questão QP1 e relata um estudo de caso de sua aplicação em uma organização do setor público. A Seção 5 relata como foi realizada a avaliação do modelo construído com base no estudo de caso. A Seção 6 discute resultados e limitações do trabalho. Finalmente, a Seção 7 apresenta as considerações finais ao trabalho ressaltando suas contribuições e oportunidades de trabalhos futuros com base no Modelo BPMG.

\section{Referencial Teórico}

O Gerenciamento de Processos de Negócio, amplamente difundido sob a denominação de BPM (sigla em inglês para: Business Process Management) é uma disciplina de gestão que ganhou corpo principalmente a partir dos anos 2000, sendo bastante influenciada pelos avanços da tecnologia de informação. BPM tem por objetivo fornecer às organizações meios de melhorar a forma como o trabalho (os processos de negócio) é realizado, buscando alinhamento estratégico, eficácia e eficiência na entrega de valor

SANTANA, A. F. L.; ALVES, C. F.

BPMG - Um Modelo Conceitual para Governança em BPM - Aplicação numa Organização Pública

isys - Revista Brasileira de Sistemas de Informação, Rio de Janeiro, vol. 9, No. 1, pp. 139-167, 2016 
aos clientes (Bruin, 2007) (Brocke e Rosemann, 2015). Nesse sentido, BPM pode ser associado ao conceito de governança de duas maneiras: (i) contribui para $o$ fornecimento de controles internos necessários como desdobramento da governança corporativa; (ii) o próprio emprego de BPM traz uma complexidade inerente à introdução de novos métodos de gestão e uso massivo de tecnologias da informação, e por isso, traz também novos riscos à organização relativos aos próprios investimentos e impactos do BPM, necessitando também de governança. Por outro lado, a aplicação do conceito de governança em BPM mostra-se um campo emergente que traz desafios e lacunas de natureza conceitual e prática para profissionais e pesquisadores da área.

De acordo com Hoogervorst (2009), embora governança não seja uma noção necessariamente recente, seu emprego foi radicalmente mudado nesta última década, tendo deixado de ser uma iniciativa voluntária para se tornar uma exigência legal, como é requerido, por exemplo, pelo ato Sarbannes Oxley de 2002. Hoogervorst (2009; pag 155) define a governança corporativa como sendo "a totalidade de estruturas e sistemas internos, bem como regras externas e legislação, de controle interno e de gestão de risco, que garante que as empresas exerçam suas responsabilidades para com os acionistas de forma eficaz e adequada". A governança costuma ser associada a princípios tais como os listados na Tabela 1.

Tabela 1. Princípios Gerais de Governança - com base em IBGC (2013), Hoogervorst (2009) e OECD (2004)

\begin{tabular}{l|l}
\hline \multicolumn{1}{c|}{ Princípio de Governança } & \multicolumn{1}{c}{ Descrição } \\
\hline Alinhamento estratégico & $\begin{array}{l}\text { Cursos de ação e objetivos em todos os níveis organizacionais devem } \\
\text { estar alinhados com a estratégia da organização (missão, visão, o } \\
\text { planejamento estratégico e seus desdobramentos). }\end{array}$ \\
\hline Efetividade & $\begin{array}{l}\text { Todas as ações organizacionais devem buscar a efetividade, aqui } \\
\text { traduzida como eficácia e eficiência ao longo do tempo no atingimento } \\
\text { dos objetivos estabelecidos. }\end{array}$ \\
\hline Equidade & $\begin{array}{l}\text { Todas as diferentes partes interessadas devem ser consideradas no } \\
\text { estabelecimento de critérios e decisões relativas às ações de BPM. }\end{array}$ \\
\hline Legitimidade & $\begin{array}{l}\text { Princípio jurídico fundamental do Estado Democrático de Direito que } \\
\text { amplia a incidência do controle para além da aplicação isolada do } \\
\text { critério da legalidade. Não basta verificar se a lei foi cumprida, mas se } \\
\text { o interesse público, o bem comum, foi alcançado. }\end{array}$ \\
\hline $\begin{array}{l}\text { Responsabilidade / Prestação } \\
\text { de Contas (Accountability) }\end{array}$ & $\begin{array}{l}\text { Deve haver sempre uma pessoa que possa ser cobrada e } \\
\text { responsabilizada por decisões e resultados de desempenho das ações } \\
\text { de BPM. }\end{array}$ \\
\hline Transparência & $\begin{array}{l}\text { Deve haver clareza de entendimento e acesso para as partes } \\
\text { interessadas sobre os critérios, decisões e resultados de ações de BPM } \\
\text { (resguardada a proteção a dados estratégicos ou sigilosos de natureza } \\
\text { legal, cuja veiculação possa prejudicar a organização). }\end{array}$ \\
\hline
\end{tabular}

Mas o que vem a ser a governança aplicada ao contexto dos processos de negócio? A literatura da área apresenta várias definições envolvendo termos similares como governança de processos, governança de processos de negócio e governança de BPM

SANTANA, A. F. L.; ALVES, C. F.

BPMG - Um Modelo Conceitual para Governança em BPM - Aplicação numa Organização Pública

isys - Revista Brasileira de Sistemas de Informação, Rio de Janeiro, vol. 9, No. 1, pp. 139-167, 2016 
que não têm uma distinção clara. A Tabela 2 apresenta alguns exemplos de definições envolvendo esses termos, bem como os principais construtos componentes da definição em questão.

Tabela 2. Algumas definições de Governança em BPM e seus principais construtos

\begin{tabular}{|c|c|}
\hline Definição de Governança de Processos / BPM & Construtos-Chaves \\
\hline $\begin{array}{l}\text { Governança de BPM como as estruturas, métricas, papéis e responsabilidades } \\
\text { adequadas para medir e gerenciar o desempenho dos processos de negócio fim- } \\
\text { a-fim da empresa. ... Envolve práticas de gestão que devem aumentar a } \\
\text { probabilidade de sucesso na implantação do plano de gestão de processos. Isto } \\
\text { inclui: o desenvolvimento de um plano de comunicação efetivo, que define quais } \\
\text { processos serão melhorados e em que prioridade; a manutenção permanente de } \\
\text { uma equipe dedicada em tempo parcial à de gestão de cada processo de negócio } \\
\text { fim-a-fim; e montagem de um pequeno grupo de especialistas no assunto com } \\
\text { conhecimentos profundos sobre os diversos aspectos de melhoria de processos } \\
\text { (“centro de excelência em processos"/ “escritório de processos”). .. Um papel } \\
\text { essencial da governança BPM é assegurar que os investimentos em TI estejam } \\
\text { intimamente ligados à estratégia de negócios da empresa, e que o retorno dos } \\
\text { investimentos de TI seja diretamente derivado das melhorias específicas no } \\
\text { desempenho de processos de negócio. Isso irá minimizar as chances de que a } \\
\text { tecnologia seja implementada em função de si própria, e deve impactar } \\
\text { positivamente a relação entre os usuários corporativos de TI e profissionais de } \\
\text { TI. Spanyi (2010) }\end{array}$ & 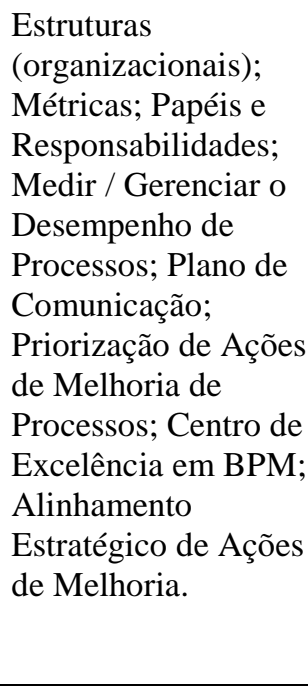 \\
\hline $\begin{array}{l}\text { A governança de processos como "a definição, difusão e controle do } \\
\text { gerenciamento de processos, no que se refere a: seus objetivos, princípios, } \\
\text { orientações e limites de decisão; forma de organização / estrutura, papéis e } \\
\text { responsabilidades; forma de avaliação e controle, que são projetados para dar o } \\
\text { nível certo de transparência e responsabilização para proteger os interesses dos } \\
\text { acionistas e partes interessadas, parceiros ou a corporação de uma forma } \\
\text { sistêmica e integrada, e assegurar que a organização não deixa de resolver } \\
\text { problemas e aproveitar as oportunidades para melhorar e inovar em como o seu } \\
\text { trabalho é feito" (Paim e Flexa, 2011). }\end{array}$ & $\begin{array}{l}\text { Ações de definição, } \\
\text { difusão e controle do } \\
\text { gerenciamento de } \\
\text { processos; Objetivos; } \\
\text { Princípios; } \\
\text { Orientações } \\
\text { (Diretrizes); Limites } \\
\text { de Decisão; Estrutura } \\
\text { Organizacional. }\end{array}$ \\
\hline $\begin{array}{l}\text { Governança de BPM como um esquema que fornece políticas, princípios e } \\
\text { convenções para o desenvolvimento e gestão coordenados dos processos. Para } \\
\text { ele a governança é parte de um framework de BPM que entre outras questões } \\
\text { coordena a padronização de processos no nível global da organização, e também } \\
\text { as eventuais necessidades de variação dos processos no nível local de unidades } \\
\text { organizacionais específicas (Tregear, 2015). }\end{array}$ & $\begin{array}{l}\text { Políticas; Princípios; } \\
\text { Convenções; } \\
\text { Padronização de } \\
\text { Processos no Nível } \\
\text { Global (Arquitetura } \\
\text { de Processos); } \\
\text { Variabilidade de } \\
\text { Processos. }\end{array}$ \\
\hline $\begin{array}{l}\text { Governança de processos de negócios refere-se à direção, coordenação e } \\
\text { controle dos indivíduos, grupos ou organizações que, pelo menos até certo } \\
\text { ponto, tem autonomia, ou seja, não estão diretamente sujeitos à mesma } \\
\text { autoridade hierárquica, tanto em processos intra quanto inter organizacionais. } \\
\text { Eles ressaltam que muitas pessoas usam o termo governança para se referir } \\
\text { principalmente aos mecanismos impessoais ou institucionais, isto é, com as leis, } \\
\text { regulamentos, normas e contratos pelos quais as relações entre os cidadãos e } \\
\text { pessoas jurídicas são arranjados (Markus e Jacobson, 2015). }\end{array}$ & $\begin{array}{l}\text { Gestão (direção, } \\
\text { coordenação, } \\
\text { controle) de pessoas, } \\
\text { equipes e unidades } \\
\text { organizacionais } \\
\text { voltadas para BPM; } \\
\text { Leis, Regulamentos e } \\
\text { Normas como } \\
\text { direcionadores da } \\
\text { Governança. }\end{array}$ \\
\hline
\end{tabular}

Na Tabela 2 podem-se então, observar:

SANTANA, A. F. L.; ALVES, C. F.

BPMG - Um Modelo Conceitual para Governança em BPM - Aplicação numa Organização Pública

isys - Revista Brasileira de Sistemas de Informação, Rio de Janeiro, vol. 9, No. 1, pp. 139-167, 2016 
- Semelhanças de construtos entre definições que usam denominações distintas. Ex: tanto a definição de "Governança de Processos" por Paim e Flexa (2011) como a de "Governança de BPM" por Spanyi (2011) trazem construtos em comum como "Estruturas" e "Papéis e Responsabilidades".

- Diferenças de construtos entre definições que usam uma mesma denominação. Ex: na definição de "Governança de BPM" por Spanyi (2010) são enfatizados os construtos "métricas" e "Estruturas" que não aparecem na definição de "Governança de BPM”, por Tregear (2015). Já Markus e Jacobson (2015) em sua definição de "Governança de Processos" enfatizam aspectos de "autonomia dos indivíduos" e "mecanismos impessoais ou institucionais", que não são encontrados na definição de "Governança de Processos" de Paim e Flexa (2011), entre outras diferenças encontráveis.

Essa confusão entre definições de governança no campo de BPM (ou de processos de negócio) e seus construtos componentes são certamente uma fonte de dúvida para praticantes quanto a que entendimento deve ser adotado em suas organizações. Além disso, a escassez na literatura de detalhamento dos construtos que compõem essa governança e a descrição insuficiente do relacionamento entre esses construtos também trazem dificuldades à implementação prática. Do ponto de vista dos pesquisadores da área, há o desafio de como comparar adequadamente abordagens que têm superposição e diferenças entre denominações e construtos?

Estre trabalho propõe um modelo conceitual de governança em BPM detalhando a conceituação dos construtos e explicitando relacionamentos entre eles como uma forma de contribuir com o entendimento conceitual e com a implementação prática dessa governança. Esse modelo é apresentado na Seção 4.

\section{Método}

Conforme os objetivos e questões de pesquisa mencionados na Introdução, o trabalho adotou as fases ilustradas na Figura 1. A primeira fase consistiu em identificar elementos conceituais que constituem a Governança em BPM visando atender à questão de pesquisa QP1. A estratégia de pesquisa adotada foi a pesquisa bibliográfica que permitiu a identificação na literatura dos elementos conceituais constitutivos da governança em BPM.

A segunda fase de pesquisa consistiu em realizar o objetivo de descrever como os elementos conceituais de Governança em BPM vinham sendo aplicados, barreiras e facilitadores relacionados, conforme a questão de pesquisa QP2. A estratégia de pesquisa adotada foi o estudo de caso exploratório múltiplo, realizado no campo de organizações públicas brasileiras. Este estudo de caso adotou uma estratégia de pesquisa qualitativa nos termos definidos por Merriam (1998) e buscou contribuir para o entendimento de como os elementos conceituais de governança em BPM encontrados na literatura estavam presentes nas organizações. Foram realizados dois estudos de caso conduzido em organizações públicas que estavam conduzindo iniciativas de BPM. No primeiro estudo foram pesquisadas quatro organizações, com entrevistas a um total de 19 profissionais envolvidos nas iniciativas de BPM destas organizações e também uma discussão em grupo focal com representantes dessas organizações. No segundo estudo de caso foram pesquisadas quatro outras organizações com entrevistas a esses estudos

SANTANA, A. F. L.; ALVES, C. F.

BPMG - Um Modelo Conceitual para Governança em BPM - Aplicação numa Organização Pública

isys - Revista Brasileira de Sistemas de Informação, Rio de Janeiro, vol. 9, No. 1, pp. 139-167, 2016 
mostraram que as organizações participantes não adotavam um modelo explícito para governança em BPM nem possuíam um entendimento suficiente do que caracteriza essa governança. Em virtude disso, vários dos elementos conceituais de governança em BPM apontados na literatura não estavam sendo aplicados nas organizações ou não eram aplicados de forma explícita. Essas conclusões foram fundamentais para consolidar o objetivo principal deste trabalho de construir um modelo conceitual como forma de apoiar um melhor entendimento e aplicação dessa governança. A realização detalhada desses estudos e seus resultados podem ser encontrados respectivamente em Santana et al (2011) e Valença et al. (2013).

Fase 1 - Identificar elementos conceituais que constituem a Governança em BPM

[QP1] Quais são os elementos que devem constituir um modelo conceitual de Governança em BPM e como eles se relacionam?

Pesquisa bibliográfica

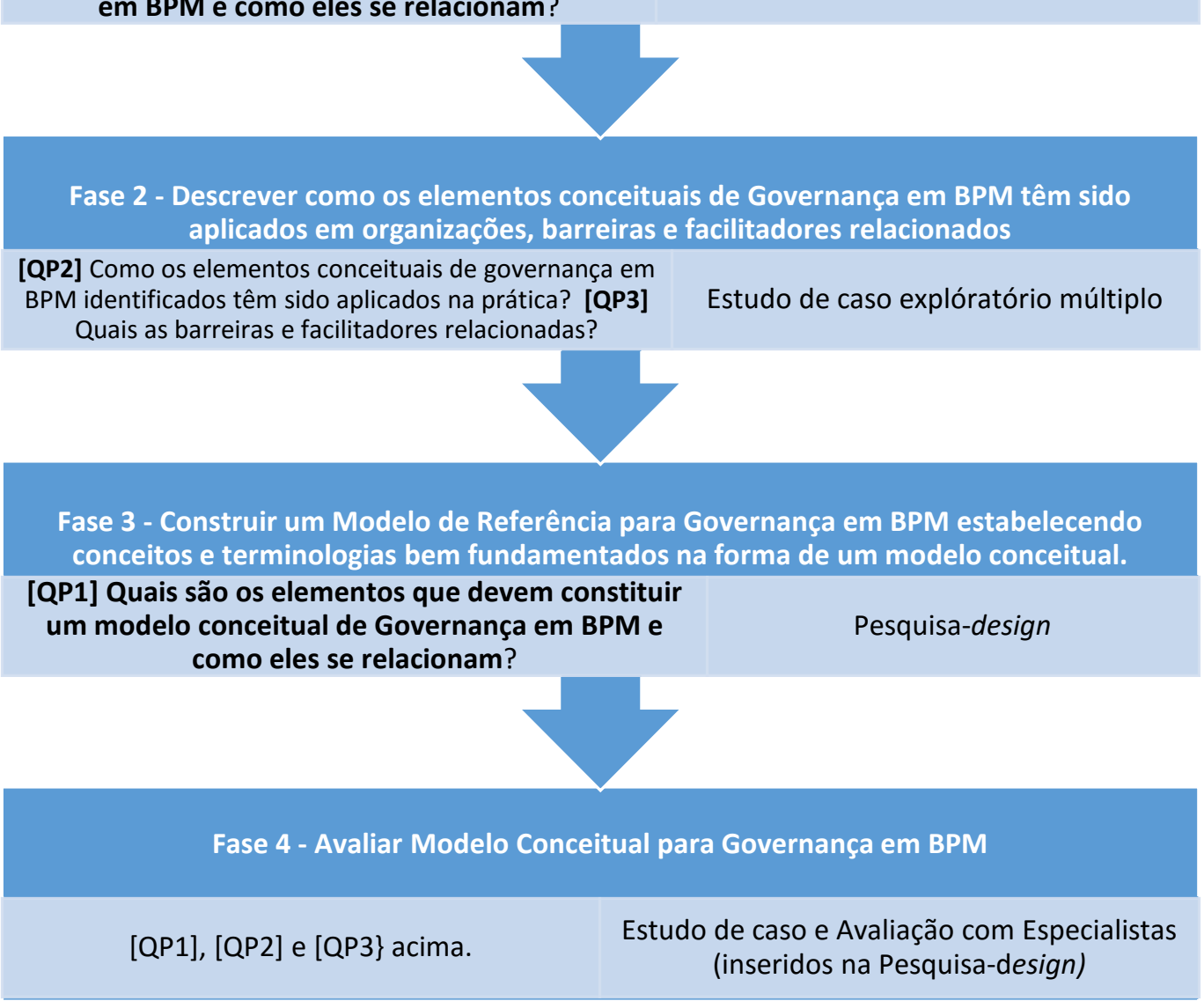

Figura 1. Fases da pesquisa

A terceira fase da pesquisa foi o núcleo central deste trabalho e consistiu em realizar o objetivo de construir um modelo de referência para Governança em BPM estabelecendo conceitos e terminologias bem fundamentados na forma de um modelo conceitual com vistas a atender à questão de pesquisa QP1. Os elementos componentes do modelo construído foram identificados a partir da pesquisa bibliográfica realizada na fase 1 explicada anteriormente. A estratégia de pesquisa adotada foi a pesquisa-design nos 
termos estabelecidos por Hevner et al. (2004) e Wieringa (2009). Conforme Hevner et al. (2004), a ciência- design (design-science) é fundamentalmente um paradigma de resolução de problema que tem suas raízes na engenharia e ciências do artificial (Simon, 1996; apud Hevner, 2004). A pesquisa-design ${ }^{1}$, que é a aplicação desse paradigma em pesquisa, destina-se a resolver os problemas humanos e organizacionais estendendo suas capacidades criando artefatos inovadores em ciclos iterativos de construir-avaliar. Artefatos de Tecnologia da Informação (TI) são amplamente definidos como construções (vocabulário e símbolos), modelos (abstrações e representações), métodos (algoritmos e práticas), e instanciações (implementações e os sistemas de protótipos) (March e Smith, 1995 apud Hevner et al., 2004). Wieringa (2009) prega que a lógica da ciência-design deve basear-se na resolução de ciclos mutuamente aninhados de problemas práticos e de conhecimento. Nesses ciclos, a solução de um problema de ordem prática pode levar o agente a fazer perguntas de conhecimento, e a obtenção de respostas a essas perguntas de conhecimento pode leva-lo a novos problemas práticos e destes, a novos problemas de conhecimento, e assim por diante. Esse mesmo autor argumenta que a abordagem de ciência-design possibilita a produção de conhecimento científico através do design de coisas úteis (artefatos) para solução de problemas práticos relacionados a problemas de conhecimento. No caso deste trabalho o artefato principal gerado foi o Modelo Conceitual BPMG descrito na Seção 4. A estratégia de pesquisa-design adotada está sintetizada na Figura 2.

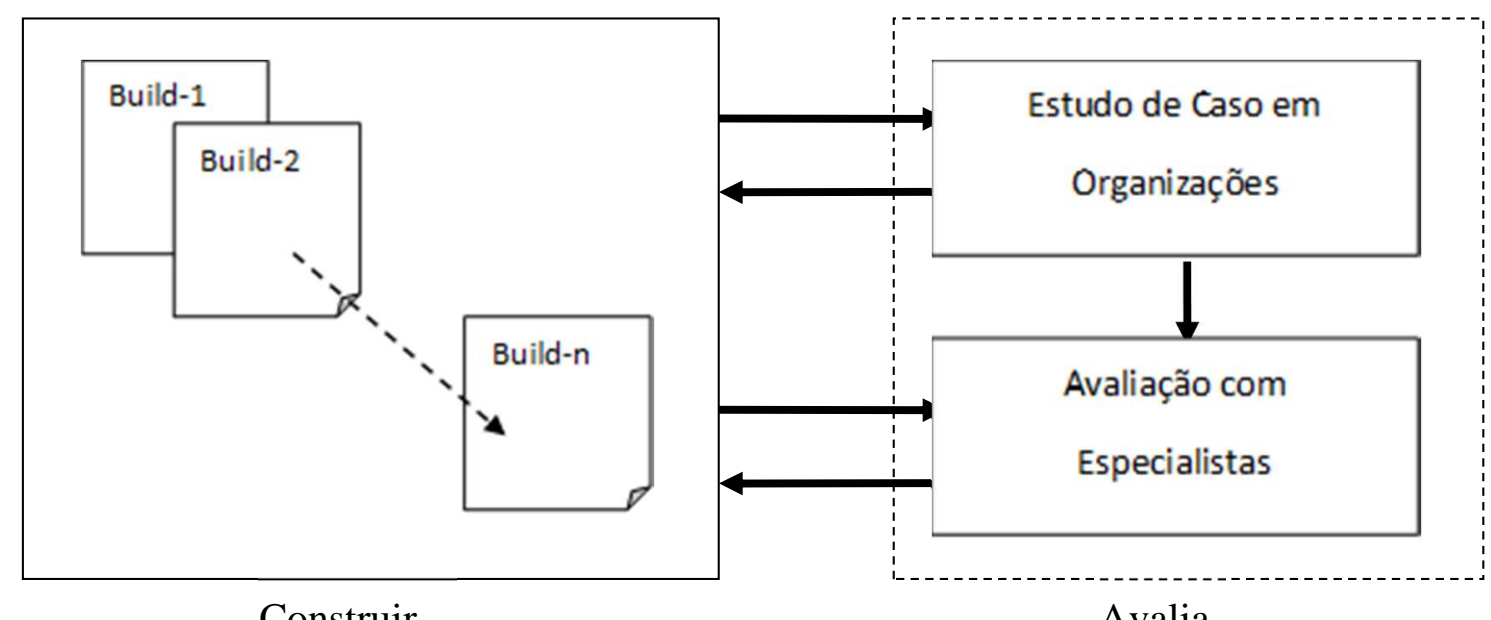

Construir

Avalia

Figura 2. Esquema de ciclo Construir-Avaliar proposto para este trabalho

A quarta fase de pesquisa realizou o objetivo de Avaliar Modelo Conceitual para Governança em BPM. Este objetivo esteve apoiado em todas as questões de pesquisa anteriormente citadas estabelecidas neste trabalho e ilustradas na Figura 1. Duas estratégias de pesquisa são aqui adotadas: um Estudo de Caso realizado numa organização pública que é detalhado na Seção 3.3, e Avaliação com Especialistas que é discutida na Seção 3.4. Os resultados dessa etapa são descritos na Seção 5.

Deve ser ressaltado que as fases de pesquisa ilustradas na Figura 1, excetuando a segunda, tiveram natureza cíclica de forma a contribuir para a melhoria do Modelo

\footnotetext{
${ }^{1}$ No original em inglês: design-research. 
Conceitual BPMG que constitui a contribuição principal deste trabalho. Os estudos de caso das fases 2 e 4 adotaram uma perspectiva de pesquisa qualitativa nos termos definidos por Merriam (1998) e foram inseridos no contexto da abordagem de pesquisadesign. De acordo com essa autora, o termo "pesquisa qualitativa" é um conceito amplo, que cobre várias formas de investigação, mas que possui o pressuposto filosófico chave comum de ver a realidade como socialmente construída pelos indivíduos em suas interações

\section{BPMG - Um Modelo Conceitual para Governança em BPM}

\subsection{O Modelo BPMG}

Entende-se aqui por modelo conceitual a mesma definição que consta no DAMA ${ }^{2}$ Dictionary of Data Management (DAMA, 2008): "Um modelo de qualquer tipo que seja independente da implementação e do contexto de uso". Um modelo conceitual normalmente é representado por modelo conceitual de dados, que por sua vez, pode ser definido como:

Um modelo de dados de alto nível, identificando as principais entidades e relacionamentos, contendo não necessariamente todos os atributos e, portanto, não necessariamente normalizado. Alguns modelos de dados conceituais incluem apenas os atributos-chave. Modelos de dados conceituais incluem relacionamentos muitos-para-muitos não-normalizados entre entidades de negócios. (DAMA, 2008 - tradução livre).

Os elementos componentes do Modelo BPMG foram identificados a partir de construtos conceituais componentes das definições de governança em BPM, obtidos em pesquisa bibliográfica conforme a fase 1 descrita na seção anterior. A definição detalhada de cada elemento bem como a identificação de suas fontes bibliográficas não é listada aqui por limitação de espaço, mas pode ser encontrada em Santana (2015. Capítulo 5).

O Modelo BPMG foi expresso na forma de um modelo conceitual de dados através de diagramas de classe na notação UML (Unified Modelig Language) (OMG, 2011). Esta notação foi utilizada por ser de amplo conhecimento, por ser suficiente para expressar os construtos básicos de um modelo conceitual de dados: as entidades do domínio em questão, seus atributos e relacionamentos (incluindo relacionamentos de "supertipo/sub-tipo" e "todo-parte"). Além disso, são encontradas diversas ferramentas de uso livre que a implementam.

A Figura 3 apresenta a visão geral do Modelo $\mathrm{BPMG}^{3}$. Os parágrafos em seguida abordam como esse modelo foi construído, bem como aspectos que influenciaram sua estrutura.

2 DAMA é um acrônimo para Data Management Association, uma associação internacional de profissionais de modelagem de dados.

${ }^{3}$ Os elementos conceituais componentes da Figura 3 foram criados em inglês visando facilitar futura internacionalização do modelo. 


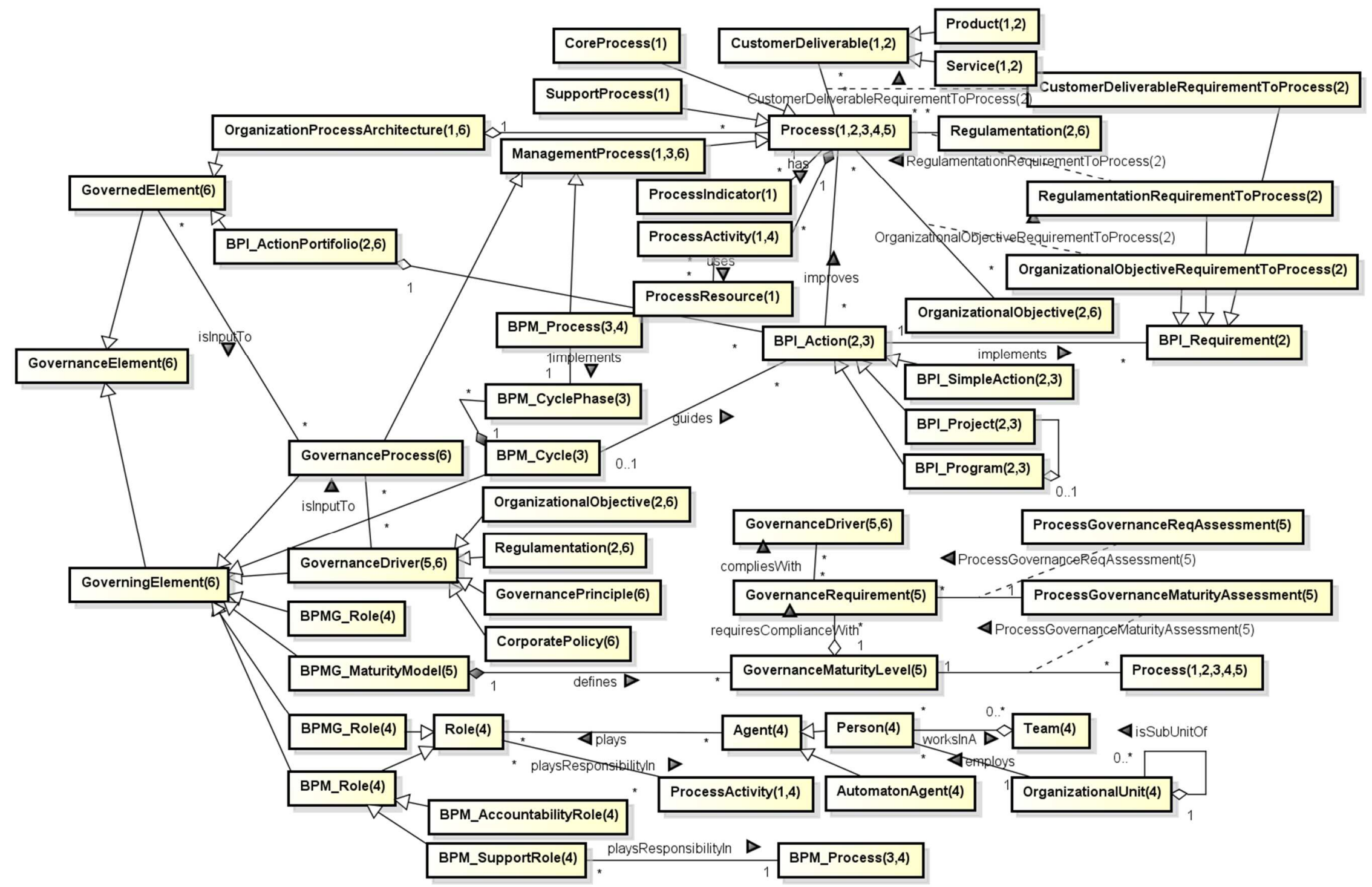

Figura 3. Visão geral do Modelo BPMG (Santana, 2015) 
Os componentes conceituais do modelo foram propostos a partir de construtos presentes em definições de Governança em BPM encontradas na literatura. A Tabela 3 a seguir apresenta um exemplo de como construtos da literatura de autores distintos deram origem a elementos do modelo. Por esta tabela pode-se observar que construtos foram agrupados por semelhança temática dando origem aos elementos do modelo BPMG. Posteriormente foram estabelecidas relações entre os elementos conceituais. Para isso foram usadas as descrições de cada elemento disponíveis na literatura, bem como a experiência dos autores da pesquisa. Em Santana (2015) são apresentadas tabelas que contêm o conjunto completo de construtos que geraram o modelo da Figura 3, que por falta de espaço não é apresentado neste artigo.

Tabela 3. Exemplo de como foram gerados os elementos do Modelo BPMG por meio do agrupamento de construtos presentes em diferentes autores

\begin{tabular}{|c|c|c|}
\hline $\begin{array}{l}\text { Agrupamento } \\
\text { de Construtos }\end{array}$ & Construto & Autor \\
\hline \multirow{3}{*}{$\begin{array}{l}\text { Objetivos de } \\
\text { BPM }\end{array}$} & Metas & Kirchmer (2010) \\
\hline & \multirow[t]{2}{*}{ Objetivos } & Barros (2009) \\
\hline & & Paim e Flexa (2011) \\
\hline Papéis & Papéis / Responsabilidades / Autoridade em BPM & $\begin{array}{l}\text { ABPMP (2013), Paim e } \\
\text { Flexa (2011), Rosemann Et } \\
\text { Al. (2010, 2008), Barros } \\
\text { (2009), Spanyi (2010) }\end{array}$ \\
\hline \multirow{3}{*}{$\begin{array}{l}\text { Arquitetura de } \\
\text { Processos }\end{array}$} & Arquitetura de Processos & Jeston e Nelis (2008) \\
\hline & $\begin{array}{l}\text { Modelo dos Processos-Chave (arquitetura de processos) da } \\
\text { Organização }\end{array}$ & Kirchmer (2010) \\
\hline & $\begin{array}{l}\text { Padronização de Processos no Nível Global (Arquitetura } \\
\text { de Processos) }\end{array}$ & Tregear (2015) \\
\hline
\end{tabular}

É importante ressaltar que no processo de construção do Modelo BPMG não foi levada em consideração uma definição específica de Governança em BPM, mas buscou-se contemplar tanto quanto possível a maior parte dos construtos teóricos identificados nas diversas definições levantadas na literatura em diversos autores. Foram levados em conta também outras fontes teóricas não necessariamente da literatura de BPM, mas de outras vertentes de Governança. Esta etapa consistiu de inúmeros ciclos de modelagem conceitual e análise dos construtos da literatura.

Cada elemento componente do Modelo BPMG é definido conceitualmente e em termos de propósito no modelo, bem como sua relação com outros elementos do modelo, conforme os exemplos a seguir:

- Definição: Conforme (ABPMP, 2013; p.432), Processo (Process) "é um conjunto de atividades interdependentes, ordenadas no tempo e espaço de forma encadeada, que ocorrem como resposta a eventos e que possui um objetivo, início, fim, entradas e saídas bem definidos. Essas atividades são geralmente interfuncionais ou inter-organizacionais que trabalham juntas para criar um produto ou serviço final. Atividades são apresentadas no contexto da sua relação entre si para proporcionar uma visão da sequência e do fluxo. Isso inclui um conjunto definido de atividades ou comportamentos realizados por humanos, 
sistemas ou uma combinação dos dois e têm um ou mais resultados que podem levar ao fim do processo ou uma entrega (handoff) a outro processo". No modelo BPMG Processo pode ser do tipo Processo Chave (CoreProcess - aquele que realiza as atividades finalistas do negócio); Processo de Suporte (SupportProcess - aquele que realiza atividades de "área meio" de apoio ao negócio); e Processo de Gerenciamento (ManagementProcess - aqueles que realizam atividades de gestão do negócio).

Propósito no Modelo BPMG: Processo é o elemento central do modelo BPMG a partir do qual se busca gerar e manter informações de apoio a Governança em BPM relacionando-a com outros elementos como: "Projeto de BPM", "Objetivo Organizacional", "Serviço", "Regulamentação", "Papel", entre outros. A partir dos relacionamentos de Processo com os demais elementos é possível gerar informações de apoio a ações que conduzam aos princípios de governança, como: alinhamento estratégico, efetividade, legitimidade, responsabilidade/prestação de contas e transparência na condução do gerenciamento dos processos de negócio.

- Definição: a Arquitetura de Processos da Organização (Organizational Process Architecture) de acordo com ABPMP (2013b; pag 414) "define processos chaves (primários), de suporte e de gerenciamento de uma organização, bem como a correlação desses processos a fluxos de trabalho e atividades necessários para a entrega de um produto ou serviço. Define também o inter-relacionamento entre processos e o relacionamento de processos com clientes e partes interessadas". Jeston e Nelis (2008; pag 86) sustenta que: "Uma arquitetura de processos assegura que:

- Processos a serem redesenhados, ou novos processos a serem desenvolvidos estão atendendo aos objetivos da organização e se adequam à estratégia da organização;

- Processos estão alinhados com a forma como o negócio é (ou deveria ser) realizado, e são capazes de fornecer os produtos e serviços aos clientes".

Propósito no Modelo BPMG: os conceitos acima têm o propósito de favorecer a efetividade, na medida em que se pode atuar na arquitetura de processos priorizando o que gera mais valor para os clientes. Favorecem também a transparência e a equidade entre os stakeholders na medida em que os esforços de melhoria podem ser localizados na arquitetura de processos da organização e associados às diferentes partes interessadas.

Conforme exemplos ilustrados acima, na definição de cada elemento do modelo buscase estabelecer sua relação com princípios gerais da governança identificados na literatura, relacionando-os assim com a governança corporativa. Por insuficiência de espaço, as definições dos demais elementos do modelo não são apresentadas neste artigo, mas podem ser encontrados em Santana (2015).

Para tornar sua compreensão e sua aplicação mais didáticas, o Modelo BPMG foi particionado em perspectivas que buscam capturar determinado aspecto da Governança em BPM. Cada perspectiva, em termos dos elementos conceituais e relacionamentos que a compõem, busca responder a questões de competência da Governança em BPM,

SANTANA, A. F. L.; ALVES, C. F.

BPMG - Um Modelo Conceitual para Governança em BPM - Aplicação numa Organização Pública

isys - Revista Brasileira de Sistemas de Informação, Rio de Janeiro, vol. 9, No. 1, pp. 139-167, 2016 
conforme a seguir. A numeração entre parênteses dos elementos do modelo na Figura 3 indica a qual perspectiva da lista abaixo pertence o elemento conceitual em questão.

1) Perspectiva da Arquitetura dos Processos - questões de competência:

- Quais são os Processos a serem governados?

- Como os Processos estão classificados na Cadeia de Valor?

- Como os Processos se relacionam com os Serviços ou Produtos entregues aos Clientes?

- Como os Processos se relacionam com Recursos da organização (aplicações em Software e Equipamentos, entre outros)?

2) Perspectiva do Alinhamento das Ações de Melhoria dos Processos com os Requisitos condicionantes de BPM - questões de competência:

○ Quais são as necessidades organizacionais que requerem ações de melhoria de processos?

- Quais necessidades organizacionais devem ser levadas em conta na priorização de ações de melhoria de processos?

- Quais são os requisitos normativos a serem levados em conta em ações de melhoria de processos?

3) Perspectiva do Ciclo de Gerenciamento dos Processos de Negócio - questões de competência:

○ Quais são as atividades de BPM e como elas se inter-relacionam?

- Dada uma determinada necessidade de melhoria de processo, que ações padrão devem ser conduzidas para realização da melhoria?

- Como um processo deve ser gerenciado e continuamente melhorado?

- Dada uma determinada ação de melhoria de processo, em que fase do ciclo de BPM ela se encontra?

4) Perspectiva da Estrutura Organizacional, Agentes e Papéis - questões de competência:

- Em quais papéis (de BPM ou de governança) uma pessoa pode atuar? Em quais ela atua?

- Dado um determinado elemento governado (exemplo: um processo, ou um projeto de melhoria de processos) quem responde pela prestação de contas desse elemento?

- Uma pessoa trabalha em qual Unidade Organizacional e é parte de quais equipes?

- Que unidades organizacionais e equipes compõem a Organização ou subáreas da organização?

- Perspectiva da Maturidade da Governança em BPM - questões de competência:

- Quais são os estágios preconizados para a governança dos processos da organização?

- Dado um estágio de governança definido, quais são os requisitos necessários que a gestão de um processo deve atender para atingir aquele estágio de governança? 
- Dado um determinado processo da organização, qual o seu estágio de governança?

5) Perspectiva dos Processos, Papéis e Direcionadores da Governança questões de competência:

- Quais são os processos da governança? Quais os papéis previstos nesses processos?

- Quais são os objetos da governança (elementos governados)?

○ Quais são os elementos direcionadores da governança?

A Figura 4 apresenta o diagrama da perspectiva da arquitetura de processos . Diagramas das demais perspectivas podem ser encontradas em Santana (2015).

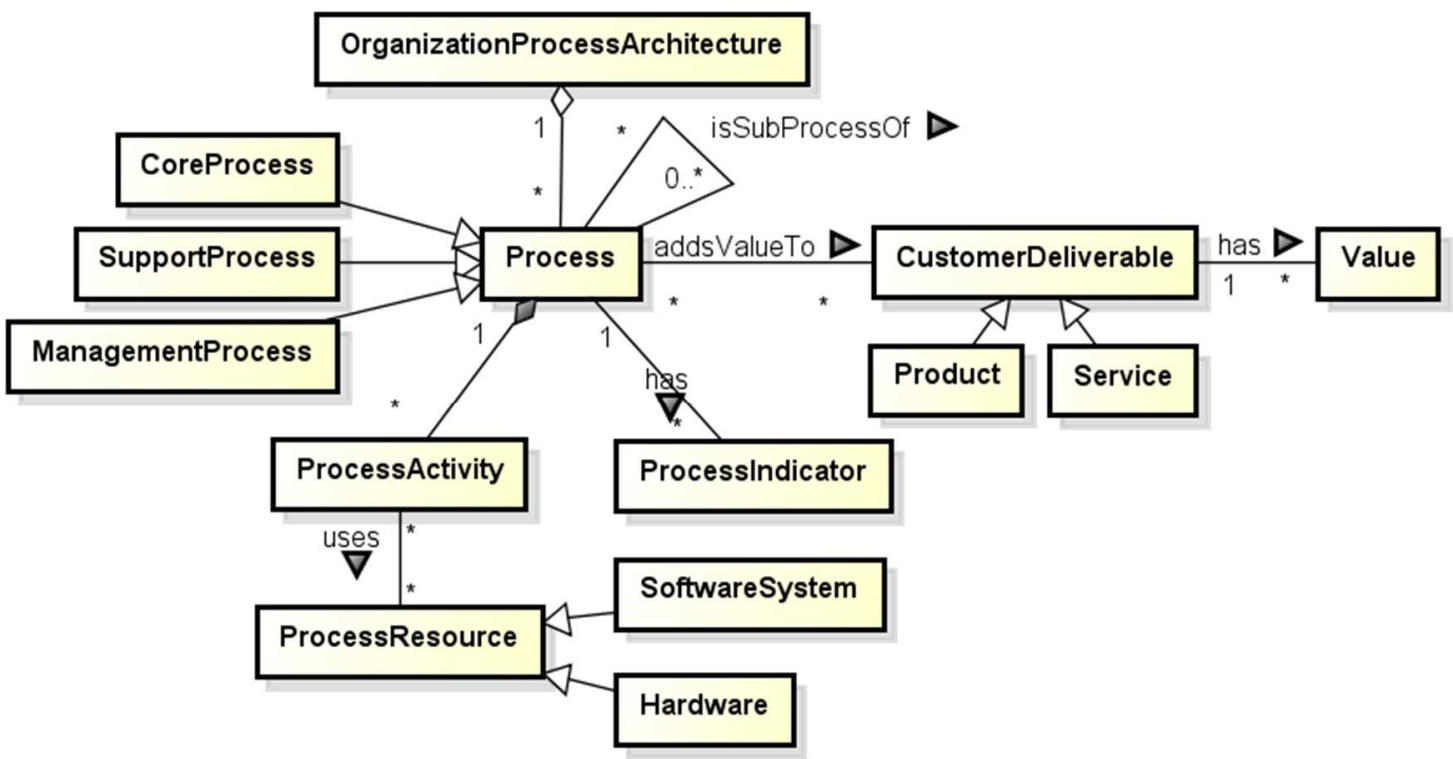

Figura 4-Perspectiva da Arquitetura de Processos, componente do Modelo BPMG

(Santana, 2015)

A estrutura do modelo foi influenciada pelo framework de Referência SOA do Open Group (2009) no sentido de propor uma distinção entre elementos governantes e elementos governados. Essa distinção intenciona esclarecer o que governa daquilo que é governado (ou seja: objeto da governança). No diagrama da Figura 3 os elementos mais à esquerda do diagrama representam essa visão de forma que os elementos governantes (GoverningElement) são os processos de governança (GovernanceProcess), os direcionadores da governança (GovernanceDriver), os elementos metodológicos Ciclo de BPM (BPM_Cycle) e Modelo de Maturidade para Governança (BPMG_MaturityModel), e os Papéis de BPM e de Governança (BPM_Role e BPMG_Role). Os elementos governados (GovernedElement) são o portifólio de ações de melhoria de processos (BPI_ActionPortifolio) e a arquitetura de processos da organização (OrganizationProcessArchitecture).

A aplicação do modelo BPMG pressupõe que o uso das perspectivas e elementos do modelo deve ser precedido de uma seleção e adaptação destes, conforme o contexto de cada organização. Desta forma, não necessariamente o modelo completo precisa ser aplicado em todos os contextos. Esse aspecto é ilustrado na Seção 4.2. 


\subsection{Aplicando o Modelo BPMG em uma Organização Pública Brasileira}

Visando possibilitar a avaliação do modelo construído buscou-se sua aplicação prática em uma organização. Nesse sentido foi desenvolvido um estudo de caso em organização pública brasileira de esfera estadual, que atua na fiscalização da legalidade e legitimidade de atos administrativos de outros órgãos públicos. Seus clientes diretos são as instituições da esfera legislativa estadual e municipal, bem como os cidadãos em geral. Nessa organização, a partir do ano de 2012, teve origem uma iniciativa para estruturar um "escritório de processos" (chamado internamente de EPROC), que atuando sob os princípios conceituais de BPM busca a melhoria dos processos da instituição.

Na perspectiva de pesquisa-design adotada, seguindo a abordagem de Wieringa (2009) já citada na Seção 3, foi adotada a concepção inicial de problemas práticos e de conhecimento conforme as Tabelas 4 e 5.

Tabela 4. Definição do Problema Prático da Pesquisa-Design

\section{Problema prático \\ Contexto do Problema Prático:}

A organização vem desenvolvendo um esforço de gestão de processos de negócio, desde 2012. Dentre as principais metas da iniciativa de BPM, destaca-se a estruturação de um escritório de processos (EPROC) em paralelo a projetos de melhoria de alguns processos de negócio da organização. Desde então, as informações sobre o esforço de BPM foram se acumulando na forma de documentos eletrônicos estáticos armazenados em pastas de rede divididas por assunto, e em aplicações de software dispersas. Por outro lado, ainda não foi estabelecido um modelo consolidado de quais dimensões de informação devem ser usadas para governança das ações de BPM. Como consequência, não há, por enquanto, meios eficientes para cruzamento das informações necessárias para avaliação de resultados, prestação de contas e planejamento dos próximos passos dessas ações.

\section{Definição dos Problemas Práticos \\ Objetivo Prático}

Como proporcionar ao EPROC e patrocinadores da iniciativa de BPM da organização um meio eficiente de gestão da informação para a governança das ações de BPM da organização? Quais são as dimensões de informação a serem consideradas?
Avaliar a viabilidade de aplicação do Modelo BPMG na construção de um catálogo eletrônico de informações voltadas para a promoção da governança em BPM.

\section{Tabela 5. Definição Problema de Conhecimento da Pesquisa-Design}

\section{Problema de Conhecimento}

\section{Contexto do Problema de Conhecimento:}

Por um lado, a governança em BPM é apontada como fator crítico para o sucesso contínuo das iniciativas de BPM. Mas, por outro lado, as abordagens de governança nesse campo têm se caracterizado por se basearem em conceitos:

○ complexos, isto é:

- O conceito amplo de Governança em BPM é apresentado como sendo composto por diversos outros componentes conceituais inter-relacionados e que possuem implicações mútuas;

○ imprecisos, isto é:

- Os componentes conceituais do conceito amplo de Governança em BPM são definidos em nível pouco detalhado;

- Diferentes componentes conceituais são usados por diferentes autores.

Como consequência, as organizações que desenvolvem iniciativas de BPM, sobretudo aquelas com baixa maturidade nesta área, não dispõem de modelos consolidados nos quais se basear para promover a governança em BPM. 


\section{Definição do Problema de Conhecimento}

Quais são e como se relacionam os componentes conceituais de um modelo de governança em BPM?

\section{Objetivo de Conhecimento}

Avaliar clareza de entendimento, utilidade, e abrangência das dimensões conceituais de informação e dos relacionamentos do modelo BPMG.

Considerando os objetivos traçados, o desenvolvimento do estudo de caso foi dividido nas seguintes etapas, que se deu ao longo de cerca de um ano:

- Etapa 1 - Seleção dos Conceitos de Governança do Modelo BPMG para aplicação na organização: essa etapa foi necessária uma vez que os conceitos até então contidos no modelo BPMG foram obtidos a partir de pesquisa bibliográfica, e não da realidade da organização. Esta seleção se deu a partir de uma pesquisa documental no repositório de documentos do Escritório de Processos complementada com entrevistas aos integrantes do escritório.

- Etapa 2 - Implementação do modelo na forma de um catálogo eletrônico de informações, denominado Catálogo BPMG, voltado para a promoção da governança em BPM. Esse catálogo consistiu em um protótipo de sistema de informação que pode ser visto em exemplo de tela ilustrada na Figura 5. O propósito dessa ferramenta foi concretizar a aplicação de elementos conceituais do Modelo BPMG, facilitando a compreensão do uso do modelo por participantes da organização e consequentemente a avaliação do Modelo BPMG. O sistema permitia o registro de instâncias dos elementos conceituais na organização e consultas referentes ao relacionamento entre esses conceitos, como por exemplo: "quais os objetivos organizacionais relacionados a um determinado processo de negócio?", ou ainda, "quais os projetos de BPM em curso estão relacionados a um determinado objetivo organizacional?".

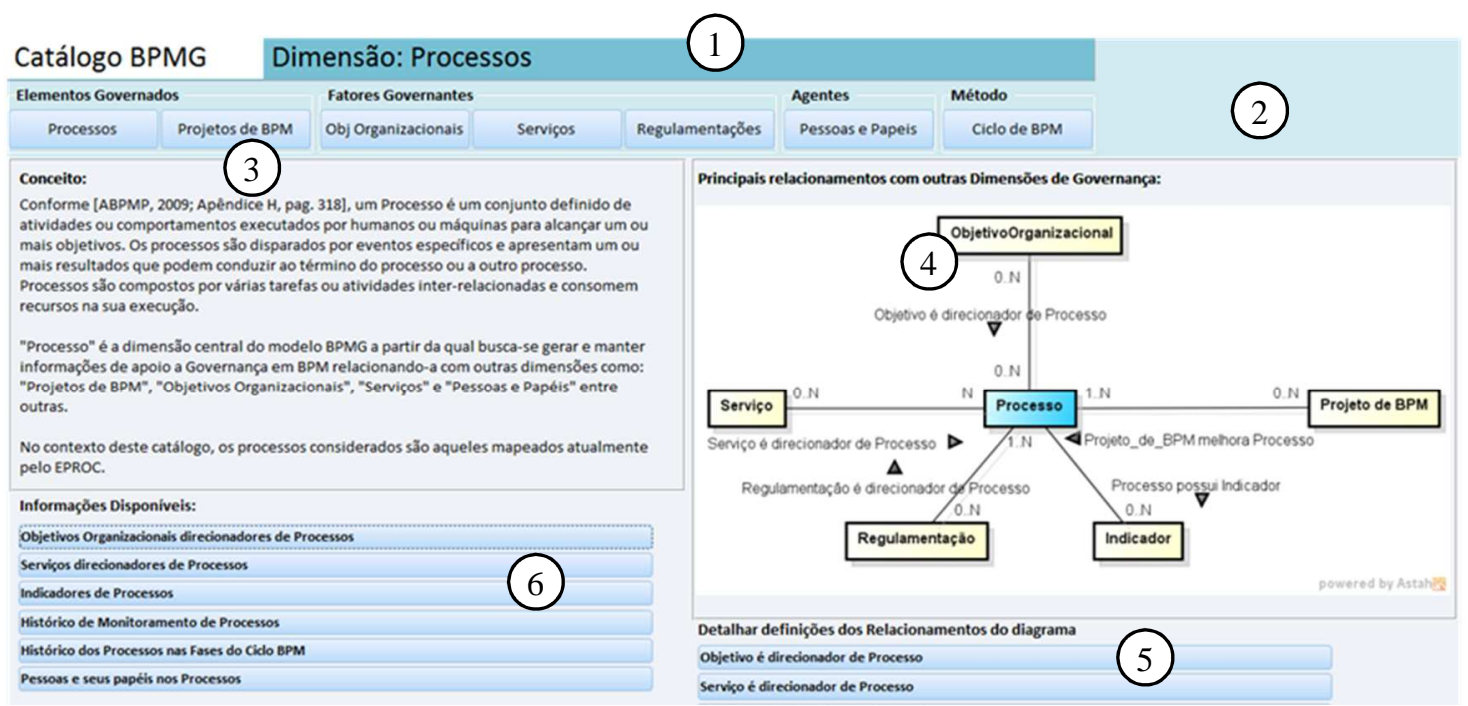

Legendas:

1) Nome da Dimensão de Governança principal representada no topo da tela.

2) Botões de navegação para as Dimensões de Governança implementadas no catálogo.

3) Conceituação da Dimensão de Governança principal representada na tela.

4)Diagrama de relacionamento da dimensão principal representada na tela com as demais Dimensões de Governança implementadas. Caixas de texto referem-se às dimensões. Setas representam os relacionamentos.

5)Botões de acesso a detalhamento dos relacionamentos (setas) entre as dimensões presentes no diagrama.

6) Botões de acesso a consultas de informações relacionadas à dimensão principal representada na tela 
Figura 5. llustração de tela do Catálogo BPMG (Exemplo ilustrado: tela da dimensão Processo)

- Etapa 3 - Avaliação do Catálogo BPMG por dois grupos distintos: (1) integrantes do Escritório de Processos da Organização e, (2) um grupo de especialistas externos em governança. Essa avaliação se deu pelo preenchimento de um questionário, no qual os elementos conceituais do Catálogo BPMG foram avaliados pelos critérios de: clareza de definição, utilidade, favorecimento aos princípios gerais de governança e abrangência conceitual.

- Etapa 4 - Discussão do Modelo BPMG em grupo focal por integrantes do Escritório de Processos da Organização. O resultado dessa avaliação é apresentado na Seção 5.

- Etapa 5 - Aplicação do Modelo BPMG na organização, com dois objetivos distintos: (1) do ponto de vista dos participantes da organização: avaliar a situação da governança em BPM na organização e identificar meios de incrementar a governança em BPM por parte do EPROC, utilizando-se do Modelo BPMG como referencial; (2) do ponto de vista do pesquisador: avaliar a clareza, utilidade e dificuldades do Modelo BPMG em uma aplicação prática, obtendo eventuais sugestões de melhoria. O resultado desta etapa foi avaliado com discussão em grupo focal e está descrito também na Seção 5.

1. Iniciação

1.1. Estabelecer grupo de trabalho para implantação do modelo

1.2. Planejar a implantação do modelo de governança em BPM;

1.3. Realizar diagnóstico inicial de Governança em BPM;

2. Adaptar o modelo conceitual para a organização;

2.1. Avaliar e aprovar o modelo

2.1.1.Estabelecer definições de referência para Governança Corporativa / Governança em BPM;

2.1.2. Estabelecer os objetivos específicos da governança de BPM na organização;

2.1.3. Selecionar elementos do modelo a serem implantados;

2.1.4.Adaptar e documentar a definição dos Elementos de Governança a serem usados na organização.

2.2. Implementar Artefatos de Informação do Modelo

Figura 6. Atividades realizadas na aplicação do Modelo BPMG na organização, adaptadas de Santana (2015, Apêndice C)

Em relação à etapa 5, considerando a previsível complexidade da aplicação desse modelo na organização foi estabelecido um escopo que fosse cabível nas possibilidades de atuação do grupo de trabalho de integrantes do Escritório de Processos, na ocasião. Assim, definiu-se que para o primeiro ciclo de trabalho de implementação do Modelo BPMG na organização, a equipe se concentraria nas atividades descritas na Figura 6. Esse escopo de atividades foi adaptado de Santana (2015; Apêndice D). Na atividade

SANTANA, A. F. L.; ALVES, C. F.

BPMG - Um Modelo Conceitual para Governança em BPM - Aplicação numa Organização Pública

isys - Revista Brasileira de Sistemas de Informação, Rio de Janeiro, vol. 9, No. 1, pp. 139-167, 2016 
(2.1.3) mencionada na Figura 6 foram selecionados os elementos de governança das perspectivas de "Arquitetura dos Processos" e de "Alinhamento das Ações de Melhoria dos Processos com os Requisitos condicionantes de BPM" referidas na Seção 4.1. Essa escolha se deu com base no diagnóstico realizado na atividade 1.3 da Figura 6, quando se constatou que o EPROC já dispunha de uma maior gama de informações referentes aos elementos componentes daquelas perspectivas. Os artefatos de informação do modelo referidos na Atividade 2.2 foram implementados em planilha eletrônica.

O trabalho na etapa 5 durou cerca de dois meses e na medida em que era desenvolvido as impressões do grupo de trabalho eram registradas em um diário para posterior análise em reuniões semanais entre o grupo e o pesquisador a fim de esclarecer dúvidas dos participantes. Para o pesquisador, o diário serviu como fonte adicional para coleta de dados sobre o desenrolar desta etapa em termos da percepção da clareza e utilidade do modelo pelos participantes.

\section{Avaliação do Modelo BPMG}

A avaliação do modelo construído mostrou-se um desafio em virtude da sua amplitude conceitual do Modelo BPMG. Desta forma, primeiramente, houve uma avaliação de um subconjunto do modelo conforme mencionado na descrição das fases 3 e 4 na Seção 4.2. A avaliação se deu por meio do preenchimento de questionários sobre os elementos conceituais selecionados e sobre o relacionamento entre esses elementos conceituais. A Tabela 6 ilustra como se deu a avaliação do subconjunto selecionado de elementos conceituais, pelos critérios de clareza e utilidade.

\section{Tabela 6. Modelo de Questões de Avaliação dos Elementos de Governança no Catálogo BPMG}

Para cada dimensão implementada do Modelo Conceitual (Processo, Projetos de BPM, Objetivo Organizacional, Serviço, Regulamentações, Papéis e Pessoas e Ciclo de BPM)

Exemplo: dimensão PROCESSO

- DEFINIÇÃO: Conforme [ABPMP, 2013; p.432], Processo é um conjunto de atividades interdependentes, ordenadas no tempo e espaço de forma encadeada, que ocorrem como resposta a eventos e que possui um objetivo, início, fim, entradas e saídas bem definidos. Essas atividades são geralmente interfuncionais ou interorganizacionais que trabalham juntas para criar um produto ou serviço final. Atividades são apresentadas no contexto da sua relação entre si para proporcionar uma visão da sequência e do fluxo. Isso inclui um conjunto definido de atividades ou comportamentos realizados por humanos, sistemas ou uma combinação dos dois e têm um ou mais resultados que podem levar ao fim do processo ou uma entrega (handoff) a outro processo.

- PROPÓSITO: "Processo" é a dimensão central do modelo BPMG a partir da qual busca-se gerar e manter informações de apoio a Governança em BPM relacionando-a com outras dimensões como: "Projetos de BPM", "Objetivos Organizacionais", "Serviços", "Regulamentações", "Pessoas e Papéis" e "Ciclo de BPM, entre outras possíveis.

\begin{tabular}{|c|c|}
\hline Questão & Objetivo \\
\hline $\begin{array}{l}\text { Como você avalia a CLAREZA DE DEFINIÇÃO desta Dimensão? } \\
\begin{array}{ll}\text { ( ) Muito Clara } & \text { ( ) Razoavelmente Clara } \\
\text { ( ) Pouco Clara } & \text { ( ) Obscura }\end{array}\end{array}$ & $\begin{array}{l}\text { Avaliar a percepção de clareza e } \\
\text { dos conceitos envolvidos }\end{array}$ \\
\hline $\begin{array}{l}\text { Numa perspectiva de Governança em BPM, como você avalia a } \\
\text { UTILIDADE desta Dimensão? } \\
\begin{array}{ll}\text { ( ) Muito Útil } & \text { ( ) Razoavelmente Útil } \\
\text { ( ) Pouco Útil } & \text { ( ) Inútil }\end{array}\end{array}$ & $\begin{array}{l}\text { Avaliar a percepção de utilidade } \\
\text { da dimensão de governança em } \\
\text { questão }\end{array}$ \\
\hline
\end{tabular}

SANTANA, A. F. L.; ALVES, C. F.

BPMG - Um Modelo Conceitual para Governança em BPM - Aplicação numa Organização Pública

iSys - Revista Brasileira de Sistemas de Informação, Rio de Janeiro, vol. 9, No. 1, pp. 139-167, 2016 
Tabela 7. Modelos de questões de avaliação dos Relacionamentos entre Elementos de Governança implementados no Catálogo BPMG

Para cada relacionamento entre os elementos do Modelo BPMG...

Exemplo: RELACIONAMENTO: "Objetivo Organizacional direciona Projeto de BPM"

- DEFINIÇÃO: Um Objetivo Organizacional direciona um Projeto de BPM quando o propósito do projeto favorece de forma significativa a realização do Objetivo Organizacional.

\begin{tabular}{|c|c|c|c|c|c|c|}
\hline QP & \multicolumn{5}{|l|}{ Questão } & $\begin{array}{l}\text { Objetivo } \\
\text { Questão }\end{array}$ \\
\hline \multicolumn{6}{|c|}{$\begin{array}{l}\text { Como você avalia a CLAREZA DE DEFINIÇÃO deste Relacionamento? } \\
\text { ( ) Muito Clara } \\
\text { ( ) Razoavelmente Clara } \\
\text { ( ) Pouco Clara } \\
\text { ( ) Obscura }\end{array}$} & $\begin{array}{l}\text { Avaliar a } \\
\text { percepção de } \\
\text { clareza e coerência } \\
\text { dos conceitos } \\
\text { envolvidos }\end{array}$ \\
\hline \multicolumn{6}{|c|}{$\begin{array}{l}\text { Em que nível você acha que as informações geradas por esse relacionamento } \\
\text { podem FAVORECER os PRINCÍPIOS DE GOVERNANÇA a seguir, em } \\
\text { relação às ações de BPM numa organização? }\end{array}$} & \multirow{8}{*}{$\begin{array}{l}\text { Avaliar a } \\
\text { percepção de } \\
\text { utilidade do } \\
\text { relacionamento } \\
\text { para com os } \\
\text { princípios de } \\
\text { Governança }\end{array}$} \\
\hline & Princípios $\backslash$ Escala & $\begin{array}{c}\text { Muito } \\
\text { [4] }\end{array}$ & [3] & {$[2]$} & $\begin{array}{c}\text { Pouco } \\
{[1]}\end{array}$ & \\
\hline & Alinhamento Estratégico & $(\quad)$ & $(\quad)$ & & & \\
\hline & Efetividade & $(\quad)$ & $(\quad)$ & & & \\
\hline & Equidade entre Stakeholders & ) & $(\quad)$ & ( & ) & \\
\hline & Legitimidade & ( & ( & ( & & \\
\hline & Responsabilidade / Prestação de Contas & ( & ) & ( & ) & \\
\hline & Transparência & $(\quad)$ & $(\quad)$ & & & \\
\hline
\end{tabular}

Cada uma das questões fechadas ilustradas nas Tabelas 6 e 7 era seguida de pela questão aberta "Comente sua resposta acima, se necessário" que visava dar espaço para aprofundar a resposta por parte dos participantes.

Essa avaliação por questionário foi realizada junto a dois grupos de participantes. $\mathrm{O}$ primeiro constou de sete integrantes do Escritório de Processos da organização do estudo de caso. O segundo grupo foi composto de sete profissionais externos à organização do estudo de caso que tinham experiência relevante em governança. A participação desse segundo grupo se deu como estratégia de triangulação de observadores da pesquisa (Runeson e Höst, 2008) visando obter maior robustez da avaliação. Considerando a limitação de espaço para apresentar aqui todos os aspectos avaliados, no presente artigo foi privilegiada a apresentação do aspecto qualitativo das avaliações, visando aprofundar a opinião dos participantes sobre o Modelo BPMG, conforme se verá a seguir neste texto. Os resultados completos desta etapa da avaliação por questionários estão disponíveis em Santana (2015, Apêndice D).

A etapa de avaliação por questionários foi complementada por uma discussão em grupo focal (Onwuegbuzie et al., 2009). Essa técnica caracteriza-se pela coleta de informações em meio a uma conversação coletiva semiestruturada de um grupo em torno de questões centrais de um fenômeno estudado. Isso permite que os membros se estimulem entre si em torno do objeto de estudo gerando informações que talvez não emergissem numa entrevista individual ou questionário. Esse procedimento foi selecionado como complementação à etapa de avaliação do subconjunto de conceitos do Modelo BPMG 
que foi implementado no Catálogo BPMG e que foi avaliado na organização estudada, conforme descrito na Seção anterior. O objetivo da discussão em grupo focal foi obtenção de dados complementares como técnica de triangulação de métodos de coleta de dados. As questões usadas para alimentar a discussão foram as seguintes: (1) de que forma o Modelo poderia ser utilizado na Organização? E: (2) que facilitadores e barreiras podem impactar o uso do Modelo BPMG na organização? A discussão foi gravada e sobre ela foi realizada uma análise temática e de conteúdo (Franco, 2005) (Freitas e Janissek, 2000) transcrevendo e agrupando os elementos discutidos. Os resultados estão sintetizados nas Tabelas 8 a 11.

Tabela 8. Discussão em Grupo Focal: Aplicabilidade do Modelo BPMG na Organização

\begin{tabular}{|c|c|c|}
\hline \# & $\begin{array}{l}\text { Aplicabilidade } \\
\text { Organização }\end{array}$ & Evidências na fala dos participantes \\
\hline 1 & $\begin{array}{lr}\text { Integrar } & \text { diferentes } \\
\text { perspectivas de } & \text { Governança } \\
\text { da organização }\end{array}$ & $\begin{array}{l}\text { "Você veio com uma ferramenta de Governança de processos, mas } \\
\text { eu enxerguei um uso bem maior pra ela, não só no EPROC, mas } \\
\text { como um elo que faltava pra integrar as perspectivas de governança } \\
\text { corporativa da Diretoria... operacionalizar a governança de forma } \\
\text { conjunta e mais efetiva... não adianta ficar fazendo controles } \\
\text { paralelos" (P1, referindo-se ao fato de que outras áreas da diretoria } \\
\text { são responsáveis por diferentes aspectos relacionados à Governança, } \\
\text { e que têm algum nível de retrabalho por falta de uma base comum de } \\
\text { conteúdo). }\end{array}$ \\
\hline 2 & $\begin{array}{l}\text { Criar um sistema corporativo } \\
\text { para governança }\end{array}$ & $\begin{array}{l}\text { "Se pegarmos esse modelo todo ajustado, instanciado (com os } \\
\text { elementos usados na organização) com as responsabilidades } \\
\text { definidas, eu posso criar um sistema” (P1). }\end{array}$ \\
\hline 3 & $\begin{array}{l}\text { Organizar e explicitar os } \\
\text { elementos componentes da } \\
\text { governança em BPM }\end{array}$ & $\begin{array}{l}\text { "O modelo ajuda a organizar o pensamento, saber de forma } \\
\text { explícita como os elementos se relacionam" (P3/ } \mathrm{P} 4) \text {. }\end{array}$ \\
\hline 4 & $\begin{array}{l}\text { Glossário para entendimento } \\
\text { compartilhado da } \\
\text { Governança em BPM }\end{array}$ & $\begin{array}{l}\text { "Serve como um grande glossário em que os termos estão definidos } \\
\text { de forma bastante exaustiva... e o modelo ajuda a estabelecer o } \\
\text { relacionamento entre as áreas... estabelecendo um diálogo comum" } \\
(\mathrm{P} 2) \text {. }\end{array}$ \\
\hline
\end{tabular}




\section{Tabela 9. Discussão em Grupo Focal: Facilitadores para Aplicação do Modelo BPMG na Organização}

\begin{tabular}{|c|c|c|}
\hline \# & Tema discutido & Evidências na fala dos participantes \\
\hline 1 & $\begin{array}{l}\text { EPROC conhecido e } \\
\text { consolidado na Organização }\end{array}$ & $\begin{array}{l}\text { "O EPROC hoje, eu acho que já é conhecido na organização } \\
\text { toda...já tem o seu 'espaço', as pessoas já sabem o que ele faz e qual } \\
\text { o seu objetivo" (P3). }\end{array}$ \\
\hline 2 & $\begin{array}{l}\text { Processo } \\
\text { implementado }\end{array}$ & $\begin{array}{l}\text { No último ano como o processo eletrônico implementado (refere-se } \\
\text { a um dos principais processos de negócio da organização, que foi } \\
\text { automatizado) }(\mathrm{P} 3)\end{array}$ \\
\hline 3 & $\begin{array}{l}\text { Momento organizacional } \\
\text { propício }\end{array}$ & $\begin{array}{l}\text { "O momento é propício (para implementar um modelo de } \\
\text { governança). Há uma necessidade inerente que todos sentem } \\
\text { (refere-se às áreas envolvidas) e cabe à gente dosar e transformar } \\
\text { isso numa coisa que seja viável (refere-se à integração das áreas } \\
\text { pelas diferentes perspectivas da governança)" (P1). }\end{array}$ \\
\hline 4 & $\begin{array}{l}\text { Quantidade (pouca) } \\
\text { pessoas envolvidas }\end{array}$ & $\begin{array}{l}\text { Um ponto positivo é que são poucas pessoas envolvidas com } \\
\text { governança aqui na diretoria }(\mathrm{P} 1) \text {. }\end{array}$ \\
\hline 5 & \begin{tabular}{lrr} 
Escritório de & \multicolumn{2}{c}{ Projetos e } \\
ferramenta & de & gestão \\
integrada de & projetos \\
consolidados & &
\end{tabular} & $\begin{array}{l}\text { "A existência de um escritório de projetos com uma ferramenta que } \\
\text {, inclusive, tem o BSC dentro dela, os indicadores estratégicos, os } \\
\text { objetivos... isso facilita bastante" (P1). }\end{array}$ \\
\hline 6 & $\begin{array}{l}\text { Planejamento estratégico } \\
\text { consolidado }\end{array}$ & $\begin{array}{l}\text { "Na verdade acho que essa consolidação (refere-se ao escritório de } \\
\text { projetos) vem desde o início, desde o planejamento estratégico bem } \\
\text { consolidado" (P3). }\end{array}$ \\
\hline
\end{tabular}

\section{Tabela 10. Discussão em Grupo Focal: Barreiras para Aplicação do Modelo BPMG na Organização}

\begin{tabular}{|c|c|c|}
\hline$\#$ & Tema discutido & Evidências na fala dos participantes \\
\hline 1 & \begin{tabular}{lr} 
Integração & \multicolumn{2}{l}{ (insuficiente) } \\
entre as áreas que \\
operacionalizam
\end{tabular} & $\begin{array}{l}\text { "Acredito que a gente tem, às vezes, é um pouco de ego...a gente } \\
\text { teria que trabalhar mais como equipe integrada... Aí o papel do } \\
\text { Diretor é fundamental" ( } \mathrm{P} 1 \text {, referindo-se ao fato de que outras áreas } \\
\text { da diretoria eram responsáveis por diferentes aspectos relacionados à } \\
\text { Governança). }\end{array}$ \\
\hline 2 & $\begin{array}{l}\text { Comunicação (fraca) sobre } \\
\text { BPM na organização }\end{array}$ & $\begin{array}{l}\text { “Nossa comunicação sobre BPM é fraca, fraquíssima... então para } \\
\text { que se use esse modelo e essa ferramenta, as pessoas têm que saber } \\
\text { não só o que é BPM, mas saber o que é 'Governança em BPM', que } \\
\text { é um tema de ponta...” (P2, com a concordância dos demais). } \\
\text { "A gente precisa vencer essa barreira da comunicação” (P2). }\end{array}$ \\
\hline 3 & $\begin{array}{l}\text { Conhecimento (falta de) do } \\
\text { conceito de governança }\end{array}$ & $\begin{array}{l}\text { "falta maturidade do conceito de governança organizacional... } \\
\text { ninguém entende direito o que é que é. Aí como vai entender o que é } \\
\text { governança em BPM?" (P1). } \\
\text { "É preciso consolidar esse conhecimento. A posição da governança } \\
\text { na organização... Isso parece 'sopa de letrinhas' (para as pessoas)" } \\
(\mathrm{P} 2) .\end{array}$ \\
\hline 4 & $\begin{array}{l}\text { Falta de entendimento } \\
\text { comum sobre } \text { conceitos } \\
\text { relacionados à gestão e } \\
\text { governança }\end{array}$ & $\begin{array}{l}\text { "Há conhecimento que é tácito, mas eu não consigo passar pra eles } \\
\text { (os clientes do EPROC): o que é uma 'necessidade'? o que é } \\
\text { 'valor'?, o que é 'cliente'? Há a necessidade de um glossário de } \\
\text { termos comuns complementares ao Modelo..." ( } \mathrm{P} 2) \text {. }\end{array}$ \\
\hline
\end{tabular}




\section{Tabela 11. Discussão em Grupo Focal: Limitações encontradas no Modelo}

BPMG

\begin{tabular}{l|l|l}
\hline$\#$ & Tema discutido & Evidências na fala dos participantes \\
\hline 1 & $\begin{array}{l}\text { Definição (falta de) de } \\
\text { termos complementares }\end{array}$ & $\begin{array}{l}\text { "Há a necessidade de um glossário de termos comuns básicos } \\
\text { complementares ao Modelo" (P2) }\end{array}$ \\
\hline 2 & Conceitos abstratos & $\begin{array}{l}\text { "Há uma necessidade de ter mais exemplificação (refere-se aos } \\
\text { elementos do Modelo)... Alguns conceitos são muito abstratos... Há } \\
\text { a necessidade de linkar o modelo com uma instanciação" (P3) }\end{array}$ \\
\hline 3 & $\begin{array}{l}\text { Catálogo BPMG em nível de } \\
\text { protótipo apenas }\end{array}$ & $\begin{array}{l}\text { "A ferramenta não está pronta para uso efetivo (refere-se ao } \\
\text { Catogo BPMG)... Precisa de uma ferramenta (refere-se a um } \\
\text { sistema de informaçôes) que realmente implemente o modelo } \\
\text { BPMG" (P5 / P2) }\end{array}$ \\
\hline 4 & $\begin{array}{l}\text { Repetição de informações no } \\
\text { Catálogo BPMG }\end{array}$ & $\begin{array}{l}\text { "Alguns elementos (do Catálogo BPMG) pareciam dar a mesma } \\
\text { contribuição que outros... a impressão é que tinha muita repetição" } \\
\text { (P1) }\end{array}$ \\
\hline
\end{tabular}

Conforme descrito na Seção 4.2, ao final da Etapa 5 de aplicação do modelo BPMG na organização foi feita nova discussão em grupo focal na qual foram abordadas as seguintes questões: (1) Como você percebeu a utilidade do modelo BPMG para o EPROC e para a Organização? (2) Que dificuldades (se houve) você teve ao lidar com o Modelo? (3) Você sentiu falta de algum elemento que deveria compor o modelo? Quais? E (4) que outras considerações você tem sobre o Modelo BPMG? O resultado da análise temática e de conteúdo dessa nova discussão está sintetizada nas Tabelas 12 a 15.

\section{Tabela 12. Discussão em Grupo Focal: Como você percebeu a utilidade do modelo BPMG para o EPROC e para a Organização}

\begin{tabular}{|c|c|c|}
\hline \# & Percepção de Utilidade & Evidências na fala dos participantes \\
\hline 1 & $\begin{array}{l}\text { Percepção sistêmica dos } \\
\text { elementos da governança }\end{array}$ & $\begin{array}{l}\text { "O modelo realmente é válido e ajuda bastante a juntar tudo e ver a } \\
\text { relação de um elemento com outro" (J / P, integrantes EPROC). } \\
\text { "Uma coisa é você ter as ideias dispersas, outra coisa é ter um guia } \\
\text { que vai servir como modelo pra gente parar e pensar sobre como } \\
\text { relacionar os elementos" (I, gerente de projetos de BPM). }\end{array}$ \\
\hline 2 & $\begin{array}{l}\text { Entendimento conceitual da } \\
\text { governança }\end{array}$ & $\begin{array}{l}\text { "Modelo é muito válido para o aspecto de entender o que é pra que } \\
\text { serve e a importância da governança dos processos" ( } / \mathrm{P} \text {, } \\
\text { integrantes EPROC). }\end{array}$ \\
\hline 3 & $\begin{array}{l}\text { Percepção de lacunas da } \\
\text { Governança em BPM na } \\
\text { organização }\end{array}$ & $\begin{array}{l}\text { ajudou bastante a ver algumas falhas que existiam aqui, que talvez } \\
\text { por fazermos anteriormente sem nenhum direcionamento a gente } \\
\text { não enxergava essas lacunas de forma tão clara, como a questão } \\
\text { dos "serviços", do "valor". (J, integrante EPROC). }\end{array}$ \\
\hline 4 & $\begin{array}{l}\text { Ajuda como guia de } \\
\text { implementação da } \\
\text { Governança }\end{array}$ & $\begin{array}{l}\text { "Pra gente aqui consolidou algumas coisas que a gente já } \\
\text { trabalhava ou pelo menos tinha ideia de trabalhar e lá no modelo } \\
\text { isso está explícito. Porque uma coisa é você ter as ideias dispersas, } \\
\text { outra coisa é ter um guia que vai servir como modelo pra gente } \\
\text { parar e pensar sobre como relacionar os elementos. Para } \\
\text { organizações que não têm nada, acho que o modelo é mais útil } \\
\text { ainda. ... Isso dá claramente a estratégia necessária pra identificar } \\
\text { que caminhos eu vou ter que seguir e que informaçôes eu vou } \\
\text { precisar trabalhar pra desenvolver a governança dos meus } \\
\text { processos" (I, gerente de projetos de BPM). }\end{array}$ \\
\hline
\end{tabular}


Tabela 13. Discussão em Grupo Focal: Você sentiu falta de algum elemento que deveria compor o modelo? Quais?

\begin{tabular}{|c|c|c|}
\hline \# & $\begin{array}{l}\text { Lacunas Conceituais no } \\
\text { Modelo BPMG }\end{array}$ & Evidências na fala dos participantes \\
\hline \multirow[t]{2}{*}{1} & $\begin{array}{l}\text { Falta explicitar o conceito de } \\
\text { "Valor". }\end{array}$ & $\begin{array}{l}\text { "Falta a representação do conceito de Valor" (J, integrante } \\
\text { EPROC; / I, gerente de projetos de BPM). }\end{array}$ \\
\hline & $\begin{array}{l}\text { Lacunas Procedimentais de } \\
\text { Apoio ao Modelo }\end{array}$ & Evidências na fala dos participantes \\
\hline 2 & $\begin{array}{l}\text { Falta dicas do que fazer com } \\
\text { lacunas conceituais na } \\
\text { organização. }\end{array}$ & (ver evidências listadas na Tabela 6.15, item 3). \\
\hline 3 & $\begin{array}{l}\text { Falta dicas de como criar os } \\
\text { repositórios de informações }\end{array}$ & (ver evidências listadas na Tabela 6.15 , item 2 ). \\
\hline
\end{tabular}

\section{Tabela 14. Discussão em Grupo Focal: Que dificuldades (se houve) você teve ao lidar com o Modelo?}

\begin{tabular}{|c|c|c|}
\hline \# & Dificuldade & Evidências na fala dos participantes \\
\hline 1 & $\begin{array}{l}\text { Ordenamento das atividades } \\
\text { de instanciação prevista no } \\
\text { guia de implantação. }\end{array}$ & $\begin{array}{l}\text { "A gente não viu como fazer um planejamento do escopo sem antes } \\
\text { fazer um diagnóstico inicial de em que ponto estava a iniciativa.". (J } \\
\text { / P, integrantes EPROC). } \\
\text { "Até pra poder identificar relacionamentos entre os elementos na } \\
\text { prática e identificar em que ponto estava a iniciativa" (I, gerente de } \\
\text { projetos de BPM). }\end{array}$ \\
\hline 2 & $\begin{array}{l}\text { Falta um guia de como criar } \\
\text { um repositório de } \\
\text { informações a partir do } \\
\text { Modelo Conceitual }\end{array}$ & $\begin{array}{l}\text { "Talvez uma falha do modelo é que ele não deixa bem claro esse } \\
\text { processo de auxiliar na criação do repositório, a questão de como } \\
\text { relacionar as informações e transformar os esquemas em } \\
\text { informações úteis. Só foi possível entender como se faria a } \\
\text { conjunção das informações depois que olhamos a ferramenta } \\
\text { (Catálogo BPMG")(J, integrante EPROC). }\end{array}$ \\
\hline 3 & $\begin{array}{l}\text { Dúvida sobre: o que fazer } \\
\text { quando informações } \\
\text { referentes a elementos do } \\
\text { Modelo não estão } \\
\text { disponíveis na organização? }\end{array}$ & $\begin{array}{l}\text { "Outra dificuldade é que é como se o modelo previsse que tudo fosse } \\
\text { ocorrer muito bem, como se de cara, quando você fosse mapear iria } \\
\text { encontrar todos os elementos e iria fazer as relações entre eles e } \\
\text { adaptar. Então quando fomos fazer a gente viu que faltava algumas } \\
\text { coisas e o modelo não deixava claro sobre o que fazer para } \\
\text { encontrar essas lacunas (J, integrante EPROC). } \\
\text { "É como se faltassem dicas... Um exemplo de lacuna: "Serviço", } \\
\text { tem no modelo, mas na organização não havia clareza sobre o } \\
\text { conceito de serviço. E nesse caso o que se faz? Para-se a } \\
\text { instanciação e vai-se cuidar dessa lacuna para depois voltar? Ou } \\
\text { deixa em aberto, para depois voltar em novos ciclos de melhoria, } \\
\text { por exemplo? Vou registrando em algum lugar para ir ficando } \\
\text { como um backlog, para tratar depois? Fazo que com essa lacuna" } \\
\text { (I, gerente de projetos de BPM). }\end{array}$ \\
\hline 4 & $\begin{array}{l}\text { Dúvida sobre: os elementos } \\
\text { do modelo têm todos o } \\
\text { mesmo nível de prioridade, } \\
\text { ou haveria alguns } \\
\text { considerados mais essenciais } \\
\text { e outros opcionais? }\end{array}$ & $\begin{array}{l}\text { "Mesmo sabendo que o modelo deve ser adaptado, até que ponto } \\
\text { determinados elementos poderiam ser dispensáveis? (Ex; Serviços). } \\
\text { Eu posso ter instanciado o modelo conforme a organização estava } \\
\text { hoje, mas não significa que eu não deveria tratar aquelas lacunas. O } \\
\text { modelo não deixa claro o que é opcional e o que é obrigatório" (J, } \\
\text { integrante do grupo trabalho; I, gerente de projetos de BPM). }\end{array}$ \\
\hline
\end{tabular}


Tabela 15. Discussão em Grupo Focal: considerações gerais

\begin{tabular}{c|l|l}
\hline$\#$ & $\begin{array}{l}\text { Lacunas Conceituais no } \\
\text { Modelo }\end{array}$ & Evidências na fala dos participantes \\
\hline 1 & $\begin{array}{l}\text { Criar backlog de } \\
\text { Implementação do Modelo } \\
\text { na Organização }\end{array}$ & $\begin{array}{l}\text { "Será interessante registrarmos em um backlog do EPROC as } \\
\text { lacunas percebidas na organização. Do contrário essas coisas irão } \\
\text { se perder" (I, gerente de projetos de BPM). }\end{array}$ \\
\hline 2 & $\begin{array}{l}\text { Criar registros de lições } \\
\text { aprendidas da } \\
\text { implementação do modelo }\end{array}$ & $\begin{array}{l}\text { "Incorporar o backlog e o diário ao processo de instanciação, para } \\
\text { registro e geração de conhecimento" (J / P, integrantes do grupo } \\
\text { trabalho; I, gerente de projetos de BPM). }\end{array}$ \\
\hline
\end{tabular}

Os resultados das avaliações relatadas nesta seção mostraram-se satisfatórios para os propósitos do Modelo BPMG. De uma maneira geral o feedback recebido indicou que o modelo se mostrou suficientemente claro e bastantes e útil para incrementar o entendimento dos participantes acerca da Governança em BPM, bem como para estruturar a aplicação dos elementos de governança na organização. As sugestões e críticas foram utilizadas para retroalimentar melhorias no modelo BPMG na perspectiva da abordagem de pesquisa-design. Desta forma, foram feitas melhorias pontuais na definição de elementos conceituais componentes do modelo e foram também acrescentados alguns elementos novos a partir de sugestões dos participantes. Para exemplificando novos elementos acrescentados, podem ser citados os conceitos: "Valor" e "Recurso de Processo", acrescentando também a este último os subtipos "Sistema em Software" e "Equipamento".

\section{Discussão dos Resultados e Limitações da Pesquisa}

Dentre as principais limitações desta pesquisa, podem-se constatar as seguintes ameaças à validade interna:

- Não foi realizada a avaliação de todos os componentes do modelo BPMG no mesmo grau de profundidade e conforme os mesmos critérios (clareza, utilidade, favorecimento aos princípios gerais de governança). Isto aconteceu porque na estratégia de avaliação do modelo no estudo de caso, foi selecionado um subconjunto de elementos do modelo para os quais foram encontradas evidências na pesquisa documental realizada na organização. Posteriormente, o modelo completo foi avaliado em discussão num grupo focal, todavia a discussão não envolveu a avaliação de cada componente conceitual de forma individual.

- A instanciação do modelo BPMG na organização se deu de forma limitada e numa escala de tempo reduzida, considerando que essa ação concorria com outras demandas do escritório de processos consideradas prioritárias na ocasião do estudo de caso. Dentre essas demandas, destacava-se um projeto em curso para automação em BPMS do principal processo da cadeia de valor da organização.

- O modelo BPMG foi avaliado numa amostragem dos participantes que foi praticamente restrita a integrantes do Escritório de Processos da organização. Desta forma, a amostra não é capaz de representar todos os segmentos da organização que podem ser stakeholders da governança em BPM. A principal razão para limitação desta amostragem deveu-se a uma conjunção de fatores: 
- A considerável falta de familiaridade com o tema governança em BPM na organização constatada na própria pesquisa;

- A demanda do tempo necessário para conhecimento do Modelo BPMG e o preenchimento do questionário de avaliação que concorriam com outras demandas dos participantes da organização e do escritório de processos, conforme já mencionado anteriormente.

Podem-se constatar também as seguintes ameaças à validade externa:

- Considerando a avaliação realizada no estudo de caso, os resultados obtidos dizem respeito apenas ao contexto daquela organização visto que o subconjunto de elementos do Modelo BPMG avaliado considerou o contexto da organização específica estudada.

- Apesar da avaliação realizada junto à especialistas em governança, a amostragem utilizada para este grupo não foi aleatória e sim intencional. A razão principal para o critério de intencionalidade decorre de que esta etapa buscou a participação de pessoas com experiência reconhecida na área de governança, buscando-se obter sugestões ao modelo.

Entretanto, as limitações apontadas anteriormente são de certa forma esperadas na abordagem de pesquisa adotada, visto que a pesquisa-design costuma ter caráter exploratório e situacional relacionado a problemas práticos em um determinado contexto, necessitando de estratégias complementares para generalização do conhecimento. Nesse sentido, o modelo resultante mostra-se relevante como ponto de partida para novas aplicações com abordagem de pesquisa-design de forma a torná-lo mais generalizável.

Com base nos resultados da avaliação apresentados, considera-se que o Modelo BPMG mostrou-se potencialmente aplicável e útil para o propósito de apoiar a Governança das ações de BPM implementadas na organização estudada. Por outro lado, constata-se que o estudo de caso serviu para a melhoria do próprio Modelo BPMG como era esperado na perspectiva da pesquisa-design, bem como abriu perspectivas de aspectos a serem explorados.

O resultado do estudo de caso foi bem-sucedido nos termos da abordagem de pesquisadesign adotada, na medida em que:

- Contribuiu para a solução do problema de conhecimento, na medida em que consolidou os componentes necessários a um Modelo Conceitual para Governança em BPM. Isso aconteceu, por sua vez, na medida em que:

- Apoiou a melhoria da clareza de definição dos Elementos Conceituais do modelo, a partir das iterações de construção-avaliação;

- Foram consolidados os componentes do modelo através da avaliação de utilidade e de sugestões a estes componentes propiciando a melhoria do Modelo BPMG

- Possibilitou o uso bem-sucedido do Modelo BPMG como referência para desenvolvimento da ferramenta "catálogo BPMG" avaliada 
positivamente como potencial repositório de informações de apoio à Governança em BPM;

- Permitiu a formulação de novos problemas de conhecimento na perspectiva da pesquisa-design, o que é um resultado interessante do estudo de caso e da pesquisa em geral;

- Contribuiu com o desenvolvimento da Governança em BPM na organização pesquisada, na medida em que:

- Propiciou um diagnóstico da situação atual dessa governança com base nos elementos do Modelo BPMG, apontando lacunas e sugestões que alimentarão os próximos passos de desenvolvimento da governança em BPM;

- Contribuiu com o amadurecimento da compreensão conceitual da governança em BPM por parte dos integrantes do escritório de processos da organização.

Vale ressaltar também que este trabalho não é necessariamente o primeiro a propor um modelo para entendimento e aplicação da governança em BPM. Os trabalhos de Barros (2009), Khusidman (2010) e Doebeli et. Al. (2015) aproximam-se do objetivo desta pesquisa no sentido de que propõem modelos para governança de processos de negócio. Entretanto pode-se verificar que, em comparação com a presente pesquisa, esses trabalhos são menos abrangentes em termos de elementos conceituais do modelo proposto, menos detalhados em termos das definições dos elementos componentes, e mais limitados do ponto de vista de sua avaliação empírica. Além disso, os modelos propostos nesses trabalhos não são apresentados em uma notação conhecida que possibilite algum nível de representação formal dos modelos, o que prejudica a precisão conceitual dos mesmos.

\section{Considerações finais e perspectivas futuras}

Até onde alcançou a pesquisa de literatura realizada, este trabalho é inovador ao propor um modelo detalhado para governança em BPM na forma de um modelo conceitual de dados que foi avaliado no contexto de uma organização e por praticantes com experiência na área. Desta forma, ele contribui de forma relevante com o estado da arte nesta área de conhecimento, na medida em que:

- Detalha, conceitua e inter-relaciona os componentes da governança em BPM em uma notação gráfica com sintaxe e semântica definidas, estabelecendo uma modelagem conceitual desses componentes. Esse aspecto, não tratado detalhadamente na literatura, é um resultado particularmente útil para o entendimento compartilhado e preciso dos conceitos entre praticantes da área, conforme foi apontado pelos participantes do estudo de caso aqui relatado. É útil também como base para implementação de aplicações baseadas nos conceitos definidos no modelo;

- Estabelece uma relação explícita entre os elementos conceituais componentes da governança em BPM com princípios gerais da governança corporativa. Esse aspecto tem se revelado uma lacuna na literatura pesquisada permite tratar a governança em BPM como um desdobramento da governança corporativa; 
- Apresenta uma avaliação empírica dos elementos conceituais componentes da governança em BPM com base em critérios de clareza, utilidade, favorecimento aos princípios gerais de governança, e abrangência conceitual na percepção de praticantes da área. Essa forma de avaliação, que não foi identificada na literatura da área, fortalece a fundamentação conceitual do campo governança em BPM;

Além disso, esta pesquisa também contribui de forma relevante com a literatura da área, na medida em que produziu dados empíricos sobre a avaliação da aplicabilidade dos elementos conceituais componentes da governança em BPM no contexto de uma organização do setor público que conduz uma relevante iniciativa de BPM. Também foram geradas novas evidências de barreiras e facilitadores para a governança em BPM, particularmente em organizações do setor público. Uma barreira particularmente significativa que foi evidenciada nas organizações pesquisadas foi a constatação da própria falta de entendimento comum do que é a governança em BPM entre os condutores das iniciativas de BPM.

Um outro aspecto significativo foi a aplicação do método de pesquisa-design (designscience research) para construção-avaliação do modelo BPMG, considerando que esta abordagem, que é particularmente útil no campo da engenharia de software e sistemas de informação em geral, tem tido ainda pouco relatos na literatura brasileira.

Este trabalho abre também novas e significativas oportunidades de pesquisa, envolvendo a evolução e extensão do Modelo BPMG, de forma a:

- O modelo pode vir a contemplar novos componentes conceituais de maneira a se constituir como modelo geral para desdobramento da governança organizacional em diferentes aspectos. Desta forma o modelo poderá conectar-se com diferentes formas de governança, como: governança de TI, governança de projetos e governança de informações, entre outras possíveis, gerando um sistema integrado de governança. Isso importante para evitar a proliferação nas organizações de modelos específicos de governança que podem conter redundância, inconsistências entre eles, e gerar retrabalho para os processos de gestão;

- A caracterização do Modelo BPMG como uma ontologia de domínio aprofundando o nível de formalismo do modelo, no sentido de classificar os elementos conceituais com base em uma ontologia de fundamentação (Guizzardi, 2010), garantindo maior consistência dos elementos;

- A aplicação do modelo em novos contextos organizacionais, gerando novos dados empíricos sobre a área de governança em BPM, bem como obter maior validação e generalização do modelo BPMG.

Referente a este último tópico, a aplicação em novas organizações do setor público paralelamente a organizações da iniciativa privada apresenta-se como uma oportunidade para identificar especificidades e diferenças à governança em BPM nestes setores. Uma questão decorrente dessa nova pesquisa poderia ser: como essas especificidades deveriam ser tratadas num modelo geral para governança? Evidências colhidas na literatura indicam que estas especificidades existem, por exemplo, em termos de maior rigidez normativa nas organizações da administração pública. Conforme (Meirelles,

SANTANA, A. F. L.; ALVES, C. F.

BPMG - Um Modelo Conceitual para Governança em BPM - Aplicação numa Organização Pública

isys - Revista Brasileira de Sistemas de Informação, Rio de Janeiro, vol. 9, No. 1, pp. 139-167, 2016 
2004 apud Machado, 2009): "Na Administração Pública não há liberdade nem vontade pessoal. Enquanto na administração particular é lícito fazer tudo que a lei não proíbe, na Administração Pública só é permitido fazer o que a lei autoriza. A lei para o particular significa 'pode fazer assim'; para o administrador público 'deve fazer assim'. (grifos nossos)". Ou ainda, conforme Moreira (2009): "O princípio da legalidade incide de forma diversa para a administração pública e para os indivíduos. Enquanto, no primeiro caso, a lei é o limite positivo da atuação, devendo toda a atuação administrativa estar abrangida em seus ditames, no segundo caso, a lei é o limite negativo, ou seja, tudo aquilo que não está proibido por lei, está automaticamente permitido. Por isso, o princípio da legalidade, no âmbito individual, é denominado de princípio da autonomia da vontade... Assim, enquanto os particulares precisam apenas de capacidade para agir em nome próprio, os agentes públicos somente podem atuar validamente se o ato estiver previsto entre suas atribuições legais" (Grifos meus). Em vista dessa maior rigidez legal, coordenar princípios de governança como a efetividade, transparência e prestação de contas (accountability) em meio às iniciativas de BPM torna-se um desafio não trivial. O Modelo BPMG aqui proposto apresenta-se como uma referência útil para implementação de elementos de governança que promovam o equilíbrio desses princípios.

\section{Referencias Bibliográficas}

ABPMP. BPM CBOK Guia para o Gerenciamento de Processos de Negócio Corpo Comum de Conhecimento ABPMP BPM CBOK V3.0, 1a Edição. ABPMP Brasil,2013.

Barros, D. B. (2009) "Governança de Processos: Proposição de um Modelo Teórico de Governança para Gestão de Processos". Dissertação de Mestrado. UFRJ/ COPPE/ Programa de Engenharia de Produção.

Brocke, J. v.; Rosemann, M. (2015) "Part II - Governance", In: Brocke, J. v.; Rosemann, M. Handbook on Business Process Management 2 - Strategic Alignment, Governance, People and Culture. 2nd Edition Springer.

Bruin, T. (2007) "Insights into the Evolution of BPM in Organisations". 18th Australasian Conference on Information Systems, Toowoomba.

Bruin, T.; Doebeli, G. (2015) "An Organizational Approach to BPM: The Experience of an Australian Transport", In: Brocke, J. v.; Rosemann, M. Handbook on Business Process Management 2 - Strategic Alignment, Governance, People and Culture. 2nd Edition Springer.

DAMA (2008) "The DAMA Dictionary of Data Management". DAMA International / Technics Publications, LLC.

Franco, M. L. P. B. (2005) Análise do Conteúdo. Brasília, Líber Livro, 2ª Edição, 2005.

Freitas, H.; Janissek, R. (2000) “Análise Léxica e Análise de Conteúdo”. Porto Alegre, Sphinx: Editora Sagra Luzzatto.

Guizzardi, G. (2010) “Theoretical foundations and engineering tools for building ontologies as reference conceptual models". Semantic Web Journal, 2010;1:3-10. 
Hevner, A. R. et Al. (2004) "Design Science in Information Systems Research". MIS Q. 2004;28(1):75-105.

Hoogervorst, J. A. P. (2009) "Corporate Governance", In: Enterprise Governance and Enterprise Engineering. Springer.

IBGC. (2013) "Origem da boa Governança". Instituto Brasileiro de Governança Corporativa - IBGC. Disponível em:

http://www.ibgc.org.br/Secao.aspx?CodSecao=18. Último acesso: Set/2013.

Jeston, J.; Nelis, J. (2008) "Business Process Management - Practical Guidelines to Successful Implementations”. Second Edition. Elsevier / Butterworth-Heinemann.

Khusidman V. (2010) “BPM Governance Framework”. BPTrends.

Kirchmer, M. (2010) "Management of Process Excellence", In: Brooke, J. vom, Rosemann, M. Handbook on Business Process Management 2 - Strategic Alignment, Governance, People and Culture. Springer.

Merriam, S. B. (1998) "Qualitative research and case study applications in education". 2. ed. San Francisco: Jossey-Bass.

Markus, M. L.; Jacobson, D. D. The Governance of Business Processes. In: Brocke, J. v.; Rosemann, M. Handbook on Business Process Management 2 - Strategic Alignment,Governance, People and Culture. 2nd Edition Springer, 2015

OECD. (2004) "OECD Principles of Corporate Governance". OECD - Organisation for Economic Co-operation and Development.

OMG (2013) "Unified Modeling Language ${ }^{\mathrm{TM}}$ (UML®)". Object Management Group, Inc., 2011b. Disponível em: http://www.omg.org/spec/UML/2.4.1/. Ultimo acesso, em: set/2013.

Onwuegbuzie, A.J. et al. (2009) "A Qualitative Framework for Collecting and Analyzing Data in Focus Group Research”. Int. J. Qual. Methods. 2009;8(3):1-21.

Open Group (2009). SOA Governance Framework. Open Group.

Paim, R.; Flexa, R. Process Governance: Definitions and Framework, Part 1. BPTrends, November 2011. Disponível em: http://www.bptrends.com/publicationfiles/11-01-2011-ART-Process GovernanceDef \%26 Framework-Paim-Flexa reviewed v1.pdf.

Rosemann, M. (2010) "The Service Portfolio of a BPM Center of Excellence", In: Brocke, J. v.; Rosemann, M.: International Handbook on Business Process Management 2 - Strategic Alignment, Governance, People and Culture. SpringerVerlag, Berlin Heildelberg.

Rosemann, M; Bruin, T. de; Power, B. (2008) "BPM Maturity", In: Jeston J, Nelis J, eds. Business Process Management - Practical Guidelines to Successful Implementations. 2nd Ed. Elsevier.

Runeson P, Höst M. (2008) "Guidelines for conducting and reporting case study research in software engineering”. Empir. Softw. Eng. 2008;14(2):131-164. 
Santana, A. F. L. (2015) "BPMG - Um Modelo Conceitual para Governança em BPM". Tese de Doutorado. Universidade Federal de Pernambuco do Programa de PósGraduação em Ciência da Computação do Centro de Informática da (CIn/UFPE).

Santana, A.F.L. et Al. (2011) "BPM Governance: An Exploratory Study in Public Organizations". Enterprise, Business-Process and Information Systems Modeling, 12th International Conference Proceedings, BPMDS 2011.

Spanyi, A. (2010) "Business Process Management Governance", In: Brooke, J. vom, Rosemann, M. Handbook on Business Process Management 2 - Strategic Alignment, Governance, People and Culture. Springer, 2010.

Tregear, R. (2015) “Business Process Standardization”, In: Brocke, J. v.; Rosemann, M. Handbook on Business Process Management 2 - Strategic Alignment, Governance, People and Culture. 2nd Edition Springer, 2015.

Valenca, G. et Al. (2013) "Understanding the adoption of BPM governance in brazilian public sector". 21st European Conference on Information Systems, June 5-8, 2013, Utrecht, The Netherlands.

Wieringa, R. (2009) "Design science as nested problem solving". Proceedings of the 4th International Conference on Design Science Research in Information Systems and Technology - DESRIST '09. 